\title{
Rates of river incision across the main tectonic units of the Pamir identified using optically stimulated luminescence dating of fluvial terraces
}

\author{
Margret C. Fuchs ${ }^{\mathrm{a}, \mathrm{b}, *}$, Richard Gloaguen ${ }^{\mathrm{a}, \mathrm{c}}$, Matthias Krbetschek ${ }^{\mathrm{b}, * *}$, Adam Szulc ${ }^{\mathrm{a}}$ \\ ${ }^{a}$ Institute of Geology, TU Bergakademie Freiberg, Bernhard-von-Cotta-Strasse 2, 09596 Freiberg, Germany \\ ${ }^{b}$ Institute for Applied Physics, TU Bergakademie Freiberg, Leipziger Strasse 23, 09596 Freiberg, Germany \\ ${ }^{c}$ Remote Sensing Group, Helmholtz Institute Freiberg of Resource Technology, 09599 Freiberg, Germany
}

\begin{abstract}
Calculated incision rates along the Panj, the main river of the Pamir, are used to investigate any influence by tectonics or climate on the architecture of the river. The depositional ages of Panj river terraces were calculated using optically stimulated luminescence (OSL) dating of terrace sand. Fluvial incision rates were generated by integrating the terrace depositional ages with accurate kinematic GPS measurements of terrace heights above the modern Panj. We investigated 16 terraces along the Panj at the western Pamir margin and one terrace from the Vakhsh River to the north of the Pamir. The results reveal brief periods of fluvial deposition over the past $26 \mathrm{kyr}$. The oldest Panj terrace depositional ages coincide with early MIS 2 and MIS 2/1 glaciations on the Pamir Plateau. Younger terrace ages have no apparent link with glacial cycles. Terraces with varying heights above the modern Panj at different localities yielded similar depositional ages. This suggests that local conditions have determined fluvial incision rates. Combining all of the terrace measurements, the average incision rate of the Panj over the last $26 \mathrm{kyr}$ has been $\sim 5.6 \mathrm{~mm} / \mathrm{yr}$. A high mean incision rate of $\sim 7.3 \mathrm{~mm} / \mathrm{yr}$ was calculated from terraces where the Panj has cut a steep-sided valley through the Shakhdara Dome. Significantly lower incision rates $(\sim 2-3 \mathrm{~mm} / \mathrm{yr})$ were calculated from terraces where the Panj flows along the southern boundaries of the Shakhdara and Yazgulom domes. At those localities, graded segments of the Panj river profile and increased valley widths are indicative of local base levels. Downstream of the Yazgulom Dome, river incision rates are generally lower $(\sim 4-5 \mathrm{~mm} / \mathrm{yr})$ than the Panj average. However, there is one exception where higher incision rates $(\sim 6 \mathrm{~mm} / \mathrm{yr})$ were calculated upstream of the Darvaz Fault Zone, a major tectonic feature that forms the western boundary of the Pamir. The Vakhsh river terrace to the north of the Pamir yielded a lower incision rate $(\sim 3$ $\mathrm{mm} / \mathrm{yr}$ ) compared to the Panj average. Variation in incision rates along the Panj does not correspond to changes in rock type or river catchment area. Instead, incision rates appear to have been primarily influenced by river capture across the southern and central metamorphic domes of the Pamir. Wherever the Panj cuts these domes it displays a convex river profile. The combination of localized river profile convexity and changes in incision rates across the Pamir domes indicates that the dome boundaries have been active recently.
\end{abstract}

Keywords: OSL dating, fluvial terraces, incision rates, Hack Index, valley shape ratios, Pamir

\section{Introduction}

The Pamir region is an excellent natural laboratory for studying the influence of tectonics and climate on fluvial processes and topographic evolution. Situated at the western end of the India-Asia collision zone, the Pamir have experienced some of the highest deformation rates on the planet (e.g., Burtman and Molnar, 1993; Pegler and Das, 1998; Reigber et al., 2001; Ducea et al., 2003; Wheeler et al., 2005). The topography of the Pamir is dominated by a series of Oligo-Miocene domes (Hubbard et al., 1999; Ducea et al., 2003; Schwab et al., 2004; Amidon and Hynek, 2010). The timing and mechanism of

\footnotetext{
*Corresponding author

** Deceased 15th October 2012

Email address: fuchm@mailserver.tu-freiberg.de (Margret C. Fuchs)
}

dome exhumation and the distribution of neotectonic activity are a focus of research in the Pamir (e.g., Schmidt et al., 2011; Schneider et al., 2013; Sippl et al., 2013; Stübner et al., 2013). The Pamir lies in a climatic transition zone between the Westerlies and the Indian Summer Monsoon (ISM). Feedbacks with topography result in climatic gradients between the margins and the plateau of the Pamir. Glacial moraines on the Pamir Plateau provide evidence for multiple glacial advances during the Late Quaternary (Zech et al., 2005a; Abramowski et al., 2006; Röhringer et al., 2012).

Drainage in the Pamir generally follows the predominantly east-west trend of the mountain ranges (Fig. 1). However, at the western margin of the Pamir the Panj river turns northwards and cuts across the southern and central Pamir domes and several major Cenozoic faults. The Panj then turns again to resume a southwesterly flow direction. 
Such anomalies in drainage architecture provide keys to unraveling the local controls on landscape evolution (e.g., Leland et al., 1998; Burbank and Anderson, 2001; Hancock and Anderson, 2002; Bull, 2007; Brookfield, 2008). The Panj cuts through one of the most tectonically active regions on the planet. The circuitous route of the Panj is advantageous as it allows the measurement of fluvial incision rates for different tectonic units of the Pamir. Relative estimates of fluvial incision such as the river profile and valley morphology suggest successive river capture events across the Pamir domes (Fuchs et al., 2013b). However, fluvial incision rates have not previously been quantified for the Panj and little is known about the spatial and temporal variations of terrace formation within the Pamir.

Incision rates can be calculated based on fluvial terraces by dividing the height of a terrace above the modern river floodplain by the age of the terrace. In erosional settings such as high mountains, fluvial terraces above a modern river record periods of fluvial stability that interrupt prevalent incision (e.g., Vandenberghe et al., 2011). The factors behind changes in the fluvial dynamic associated with sediment deposition, terrace abandonment and subsequent incision may be complex because of the interplay of tectonics and climate (e.g., Pazzaglia et al., 1998; Burbank and Anderson, 2001; Formento-Trigilio et al., 2002; Pan et al., 2009). Globally compiled fluvial records indicate that terrace formation is primarily a consequence of tectonic uplift combined with cyclic climate (e.g., Bridgland and Westaway, 2008; Westaway et al., 2009). The cyclic glaciations of the Quaternary have played an important role in triggering sediment generation and water discharge (e.g., Hancock and Anderson, 2002; FormentoTrigilio et al., 2002; Wang et al., 2009). Tectonic uplift causes relative base level lowering that is an important precondition of terrace incision and preservation (e.g., Bridgland and Westaway, 2008; Vandenberghe et al., 2011). Without relative uplift, fluvial sediments rather form stacked or over- and onlapping deposits as observed, for example, in sedimentary basins (Vandenberghe et al., 2011). Differential uplift may further cause small-scale variations in stream power across tectonic units that lead to the formation of localized terraces between areas of relative subsidence (Vandenberghe et al., 2011). However, the interpretation of incision rates in terms of relative bedrock uplift rates or climatic control is debated. It requires careful evaluation of intrinsic effects of the studied fluvial systems such as timescale dependencies or river channel evolution (e.g., Burbank et al., 1996; Leland et al., 1998; Carcaillet et al., 2009; Pan et al., 2009; Vandenberghe et al., 2011; Finnegan et al., 2014).

OSL dating of terrace sediments provides a maximum age of terrace abandonment. OSL dates the last time a sediment has been exposed to light. Assuming the sediment has had no contact with light since initial burial this age has important uses in geomorphologic studies. Advantageous is that OSL dating can be applied to quartz grains, a ubiquitous component of sediment. Compared to feldspars, the other commonly used mineral in luminescence dating, quartz does not show anomalous fading (Wintle, 1973) and has a faster signal reset (Wallinga, 2002). However, in mountain settings the OSL properties of quartz have been found to be problematic (e.g., Preusser et al., 2006; Fuchs et al., 2013a) due to low sensitization related to few sedimentation cycles (e.g., Pietsch et al., 2008; Jeong and Choi, 2012). In such settings OSL dating of quartz requires additional attention to measurement parameters. Another essential question concerns the degree of signal reset (bleaching) during fluvial transport. Especially in mountainous areas, peak discharge in the melting season and high sediment loads can cause incomplete bleaching of grains. Such sediments require statistical dose distribution analyses to select the appropriate age model (e.g., Galbraith et al., 1999).

Here, we combine optically stimulated luminescence (OSL) dating of fluvial terraces and kinematic GPS measurements of terrace heights above the present river to quantify local fluvial incision rates along the northwarddeflected Panj and its downstream reaches. To address differential bleaching and ensure a correct paleodose determination, we apply statistical age models to the measured data sets (e.g., Bailey and Arnold, 2006; Arnold et al., 2007). OSL-based local incision rates and their variations are set in context by analyzing the longitudinal profile of the Panj and utilizing Hack Indices as long-term morphometric indicators (Hack, 1973; Snyder et al., 2000; Singh and Awasthi, 2010; Stokes et al., 2012). We compare the pattern of fluvial incision rates to valley morphology perpendicular to the modern river, quantified by measuring the valley shape ratio (VSR) (Fuchs et al., 2013b). We discuss the potential forcing from glacial cycles during the Late Quaternary as well as the relevance of changes in rock types and increases in catchment area for explaining the spatial variations of fluvial incision.

\section{Study area}

\subsection{Tectonic setting}

Lying at the northwestern end of the India-Asia collision zone (Fig. 1), the Pamir comprises a series of Paleozoic to Mesozoic sutures, magmatic belts and crustal blocks (e.g., Burtman and Molnar, 1993) that formed a steady state elevated plateau since the onset of the Cenozoic (Ducea et al., 2003). The tectonic units are assumed to be along-strike equivalents of the Tibetan Plateau that accreted to the Eurasian plate (e.g., Cowgill, 2010; Bershaw et al., 2012). In particular, the Cretaceous arc-type granitoids in the Central and Southern Pamir have been linked to equivalents in Tibet. However, the details of such correlations are still debated (e.g., Schwab et al., 2004; Robinson, 2009).

The domes cover up to $30 \%$ of the Pamir and expose crystalline basement and metamorphic rocks (Vlasov et al., 1991; Brunel et al., 1994; Schwab et al., 2004; Robinson 


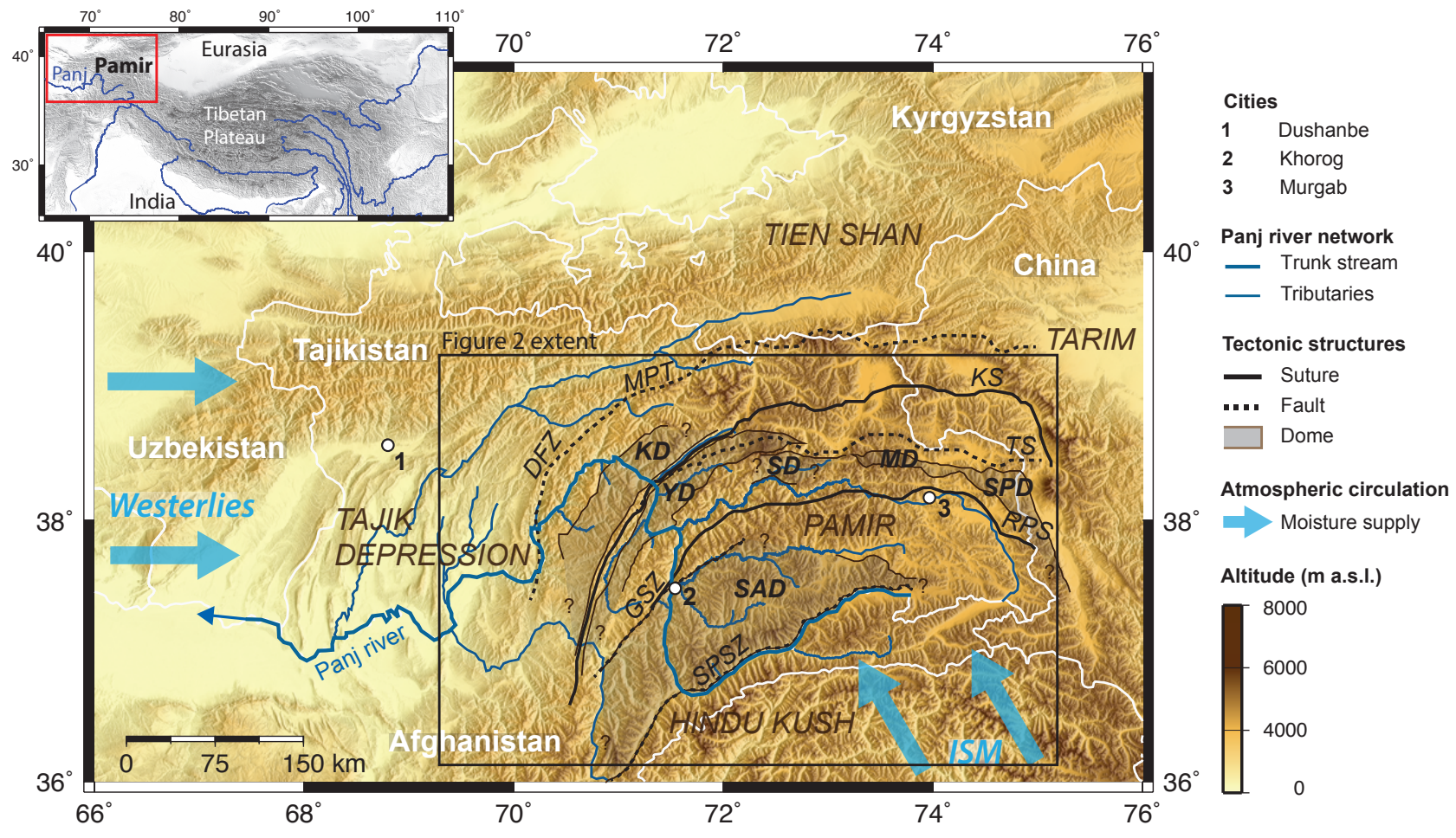

Figure 1: Regional setting of the Panj river network. Map of the Pamir with drainage network, main geological structures and atmospheric circulation (m. a.s.l.: meters above sea level, KD: Kurgovat Dome, YD: Yazgulom Dome, SD: Sarez Dome, MD: Muskol Dome, SPD: Shatput Dome, SAD: Shakhdara-Alichur Dome, DFZ: Darvaz Fault Zone, MPT: Main Pamir Thrust, KS: Kunlun Suture, TS: Tanymas Suture, RPS: Rushan-Psart Suture, GSZ: Gunt Shear Zone, SPSZ: Southern Pamir Shear Zone, white line: national boundaries, ?: unknown extent of tectonic structure). Modified after Fuchs et al. (2013b)

et al., 2007; Schmidt et al., 2011; Stübner et al., 2013) The Kurgovat Dome of the Northern Pamir consists of high-grade metamorphosed Triassic rocks. The domes in the Central Pamir (Yazgulom, Sarez, Muskol and Shatput domes; Fig. 1) and the Southern Pamir (Shakhdara and Alichur domes) have exhumed high-grade metamorphic rocks of Oligocene-Miocene age (Schmidt et al., 2011; Stübner et al., 2013). The Pamir gneiss domes relate to orogen-wide exhumation between $\sim 21 \mathrm{Myr}$ and $13 \mathrm{Myr}$ (Lukens et al., 2012). Dome exhumation in the eastern Pamir has remained constant since $7 \mathrm{Myr}$ (Robinson et al. 2010). Thermochronology indicates that exhumation of the Shakhdara and Yazgulom domes reached a peak at $\sim 15 \mathrm{Myr}$ and continued until at least $\sim 2 \mathrm{Myr}$ (Stübner et al., 2013).

Neotectonic activity is focused at the active frontal range of the Pamir that bends almost $180^{\circ}$ from northern Afghanistan into western China (Bershaw et al., 2012). The indentation of the Pamir into Eurasia has involved two intermediate-depth intra-continental subduction zones that are resolvable by seismicity and tomography (southern Tien Shan-Pamir and Hindu-Kush-Pamir slabs; e.g. Koulakov and Sobolev, 2006; Schneider et al., 2013; Sippl et al., 2013). GPS measurements show northward shortening of $\sim 15 \mathrm{~mm} / \mathrm{yr}$ across the Main Pamir Thrust (MPT) and $\sim 10 \mathrm{~mm} / \mathrm{yr}$ south of Pamir across the Hindu Kush and Chitral Himalaya (Ischuk et al., 2013). The lateral margins of the orocline accommodate transtension to the east along the Karakoram Fault Zone (KFZ) and transpression to the west along the Darvaz Fault Zone (DFZ, cf. Fig. 1). Late Quaternary lateral motion across the DFZ reaches $\sim 12 \mathrm{~mm} / \mathrm{yr}$ (Trifonov, 1978; Mohadjer et al., 2010). The strike-slip faults in the south-eastern Pamir that root in the KFZ display low lateral displacement rates of $<1 \mathrm{~mm} / \mathrm{yr}$ (Strecker et al., 1995). The southern boundary is complex but indicates a major east-west, low-angle normal fault that bounds the Shakhdara Dome to the south, referred to as Southern Pamir Shear Zone (SPSZ, cf. Figs. 1, 2, own field observations and Stübner et al. 2013). Away from the Pamir boundaries, seismic records indicate an intra-plateau neotectonic activity that relates to the east-west extension of the Karakul rift system, and scattered seismic activity in the Southern Pamir (e.g., Fan et al., 1994; Strecker et al., 1995; Sippl et al., 2013).

\subsection{Present and past climatic conditions}

Data from the Tropical Rainfall Measurement Mission (TRMM, 3B42 V7 product) shows that the Westerlies supply most precipitation to the western margins of the Pamir 


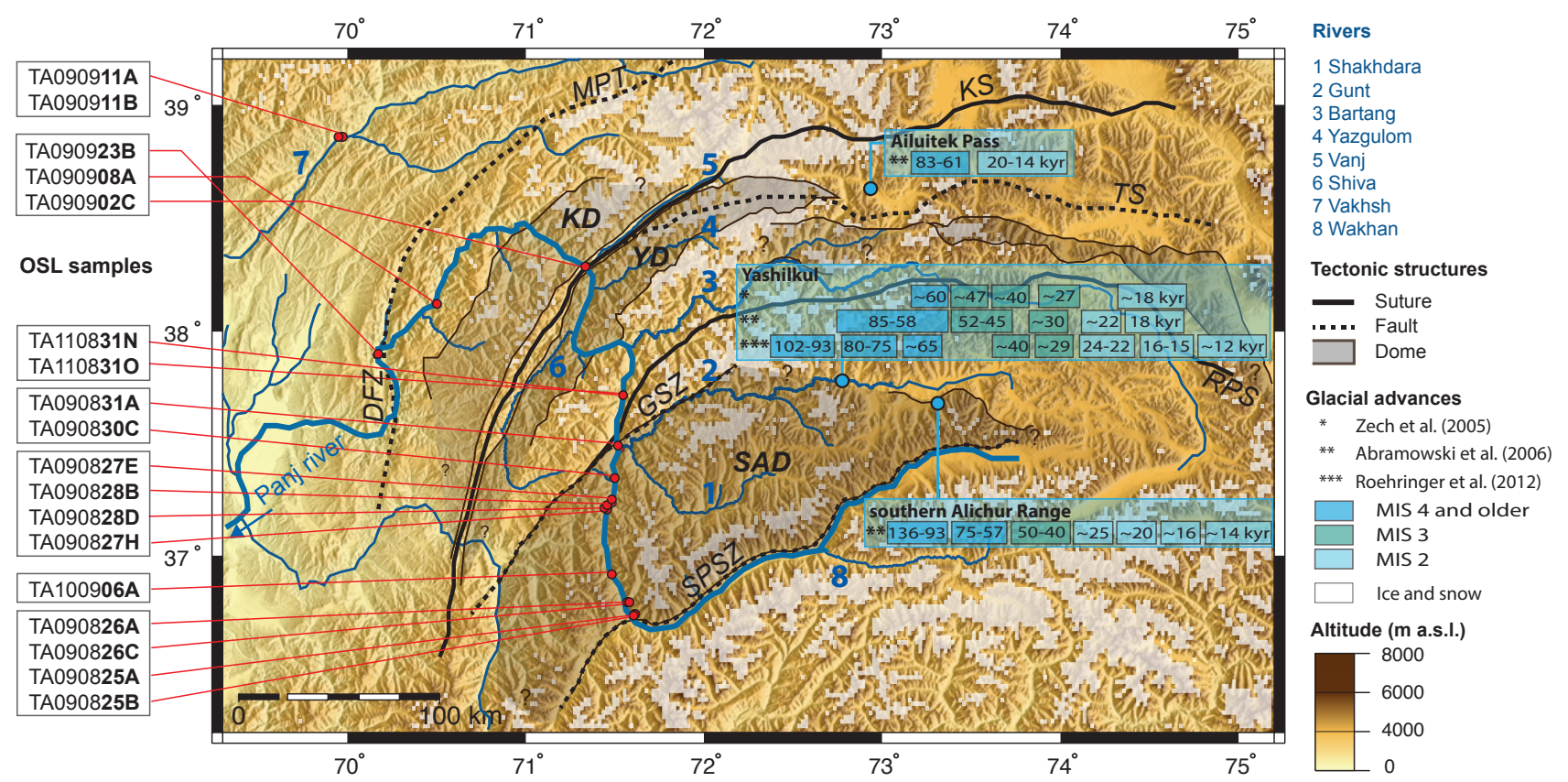

Figure 2: Location of fluvial terraces along the Panj and Vakhsh rivers that were sampled for OSL dating. Potential control factors include topography (m. a.s.l.: meters above sea level), and major tectonic structures (KD: Kurgovat Dome, YD: Yazgulom Dome, SAD: ShakhdaraAlichur Dome, DFZ: Darvaz Fault Zone, MPT: Main Pamir Thrust, KS: Kunlun Suture, TS: Tanymas Suture, RPS: Rushan-Psart Suture, GSZ: Gunt Shear Zone, SPSZ: Southern Pamir Shear Zone, white line: national boundaries, ?: unknown extent of tectonic structure) and distribution of permanent snow and ice cover (MODIS MCD12Q1, Strahler et al. 1999, year 2010, Land Cover Classification according to the International Geosphere Biosphere Programme). Additionally, we display the timing of glacial advances inferred from three sites at the Pamir Plateau (blue to greenish boxes in the map, numbers represent ${ }^{10} \mathrm{Be}$-based moraine ages in thousand years (kyr), ${ }_{-}^{*} * * *$ : reference annotations of individual glacial chronologies, references are given in the map legend).

during winter and spring. To the south, summer precipitation from the Indian Summer Monsoon (ISM) rapidly attenuates over the Hindu Kush and Karakoram Range before reaching the Pamir. Both result in considerable precipitation gradients and a westward displacement of permanent ice and snow cover. The central plateau regions receive little rainfall, mainly in the form of snow. Plateau glaciers are small (Fuchs et al., 2013b).

The position of the Pamir at the transition between the Westerlies and the ISM means the region is particularly sensitive to changes in atmospheric circulation patterns (Zech et al., 2005a). Glacial advances particularly during the Late Quaternary likely affected the drainage evolution by changing transported sediment volumes and river discharge and therefore may have triggered the development of river terraces along the Panj. Information regarding the Quaternary glacial chronology of the Pamir is limited to few study sites on the Pamir Plateau (Zech et al., 2005a; Abramowski et al., 2006; Röhringer et al., 2012). A chronology for local glacial landforms at lower altitudes in west-trending valleys has yet to be established.

There is a synchronicity between the Quaternary glaciations and Northern Hemisphere cooling cycles during MIS 4 and MIS 2 (Fig. 2), indicating the dominance of the Westerlies (Abramowski et al., 2006; Owen et al., 2008). Pro- gressively less extensive advances suggest links to an increasing aridity throughout the Late Quaternary in Central Asia due to a strengthened Siberian High (Abramowski et al., 2006).

However, the most extensive glacial advances on the Pamir Plateau occurred during MIS 4 or earlier during MIS 5 - 6. Cosmogenic nuclide dating of the moraine yielded two age clusters of $136-93 \mathrm{kyr}$ and $86-60 \mathrm{kyr}$ (Zech et al., 2005a; Abramowski et al., 2006; Röhringer et al., 2012). The oldest glacial moraine from the Lake Yashilkul, the Southern Alichur Range and the Ailuitek Pass indicates the presence of paleo-glaciers down to the intra-plateau valley floors at $\sim 3600 \mathrm{~m}$ a.s.l.. Hummocky moraines accompanied by two lateral moraine ridges indicate a glacial advance during MIS 3, which is synchronous with an increased influence of the ISM (Zech et al., 2005a; Röhringer et al., 2012) as reported from the Hindu Kush, Karakoram Range and Tibet (e.g., Owen et al., 2002b,a, 2008, 2012). Additional scattered younger ages are interpreted as prolonged ice degradation and/or glacial recession (Zech et al., 2005b). Two less extensive glacial advances between 37 $30 \mathrm{kyr}$ (MIS 3/2) and 24- $22 \mathrm{kyr}$ (MIS 2) pre-date the LGM (Zech et al., 2005a; Abramowski et al., 2006; Röhringer et al., 2012). Minor glacial advances have been identified at $\sim 16 \mathrm{kyr}$ and $\sim 12 \mathrm{kyr}$ during an overall period of glacial 

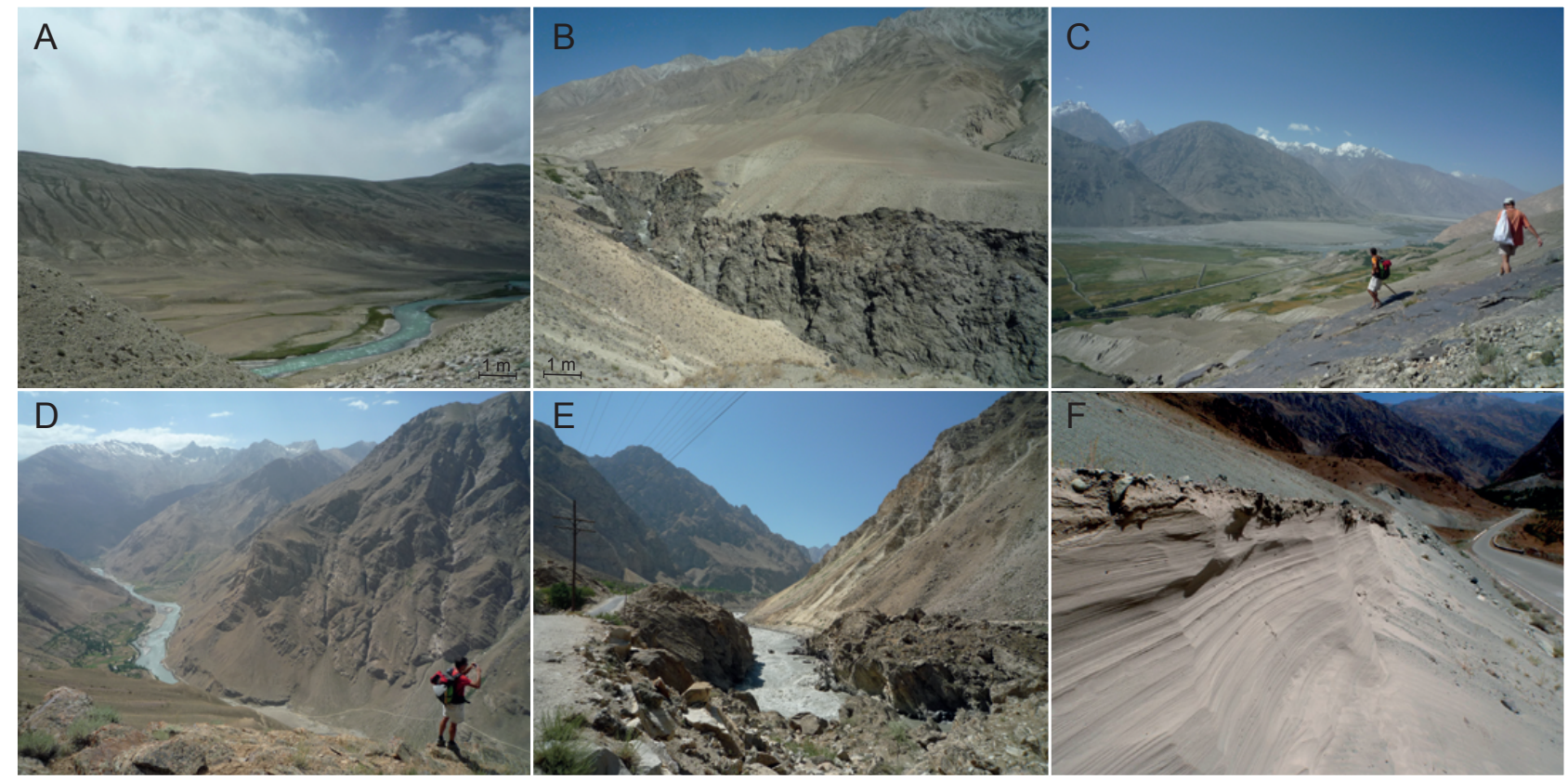

Figure 3: Valley morphology of the Panj. A: Uppermost Panj reach (Pamir River) in wide valley with extensive sediment fills, B: Deep canyon incised into bedrock at the margins of the Pamir Plateau, C: Wide valley with low riverbed slopes, braided river perturbed by lateral fan sedimentation, D-F: Steep valleys with debris and alluvial fan deposits that are cut and removed by the Panj. Fluvial sediments are locally restricted to a few localities and indicate only short-term periods of deposition.

retreat (Röhringer et al., 2012).

\subsection{The Panj river network}

The Panj river originates at the south-eastern Pamir Plateau (Fig. 3A). Flowing along the southern and western Pamir margins, it drains most of the Pamir towards the west into the Tajik depression. The Panj drainage basin is strongly asymmetric with predominantly westward draining rivers (Fig. 2). Tributaries join the Panj at the western Pamir margin, close to the drainage divide. The northward-deflected reach of the Panj parallels the south-bending DFZ and cuts across the Shakhdara and Yazgulom domes. Valley morphometries (Fig. 3A-F) and the longitudinal profile indicate that the Panj is a composite, non-equilibrated river (Fuchs et al., 2013b). Steep valleys (Fig. 3B, D-F) and prominent convex zones along the river profile suggest three successive river capture events (Fuchs et al., 2013b). The non-equilibrated, convex zones connect reaches where the Panj develops a more concave profile with wider valleys (Fig. 3C). The more graded Panj reaches suggest local base levels at the southern dome boundaries of westward-oriented valleys. In this context, the term local base level refers to the base level that the fitted profiles respond to (details on profile analyses of the Panj are given in Fuchs et al. 2013b).

\section{Methodology}

\subsection{Investigated fluvial terraces}

The fluvial terraces investigated in this study are located along the northward-deflected Panj and its downstream reaches (Figs. 2, 3 D-F). These were sampled for OSL dating to determine variations in fluvial incision rates across the main tectonic units of the Pamir. In this part of the Panj, the terraces comprise relatively rare, discontinuous fluvial deposits. Their formation is not regionally consistent, as indicated by the lack of continuous valley fills and paired terraces. The narrow and steep valleys of the northward-deflected reach of the Panj with limited sedimentation indicate the predominance of fluvial incision. Layers of coarse fluvial sand are in most cases $\sim 1 \mathrm{~m}$ thick, reaching $2-4 \mathrm{~m}$ at a few localities (TA31N, TA31O, TA02C, TA11A and B). The north-trending reach of the Panj incises bedrock and deposited sediment forms isolated beaches (Fig. 4B, C).

Sixteen fluvial terraces from different localities along the Panj were sampled (Fig. 2). Additionally, one terrace from the Vakhsh River was sampled to test for any difference in incision rate north of the Main Pamir Thrust. Selected terraces were layered, well-sorted and composed of quartz-rich sands. These outcrop as lenses several meters in length. Only terraces that clearly originated from the trunk river were sampled. Sample positions were located using multi-frequency post-processing kinematic GNSS (PPK) techniques. Apart from exact longitude and lat- 
Table 1: Location and description of sampled terraces ( $\mathrm{m}$ a.s.l.: meters above sea level, $\mathrm{m}$ a.r.l.: meters above local river level). Bold letters in sample names indicate notations used in the text.

\begin{tabular}{|c|c|c|c|c|c|c|}
\hline Location & Sample & $\begin{array}{l}\text { Position } \\
\text { Latitude } \\
{\left[{ }^{\circ} \mathrm{N}\right]}\end{array}$ & $\begin{array}{l}\text { Longitude } \\
{\left[{ }^{\circ} \mathrm{E}\right]}\end{array}$ & $\begin{array}{l}\text { Altitude } \\
{[\mathrm{m} \text { a.s.l. }]}\end{array}$ & $\begin{array}{r}\text { Terrace heights } \\
{[\mathrm{m} \text { a.r.l. }]}\end{array}$ & Sediment description \\
\hline Ishkashim & TA090826A & 36.813 & 71.555 & 2425 & 13.0 & Layered medium sand \\
\hline Ishkashim & TA090826C & 36.792 & 71.568 & 2454 & 24.9 & Lens of medium sand \\
\hline Ishkashim & TA090825A & 36.739 & 71.610 & 2850 & 191.0 & Layer of silt to fine sand \\
\hline Ishkashim & TA090825B & 36.737 & 71.610 & 2746 & 68.0 & Lens of medium sand \\
\hline Sanjut & TA100906A & 36.903 & 71.526 & 2613 & 151.0 & Layer of medium sand \\
\hline Andarop, south & TA090827H & 37.216 & 71.461 & 2259 & 20.7 & Lens of fine to medium sand \\
\hline Andarop, south & TA090828B & 37.219 & 71.460 & 2236 & 6.3 & Layer of medium sand \\
\hline Andarop, south & TA090828D & 37.219 & 71.462 & 2246 & 15.3 & Layer of fine to medium sand \\
\hline Andarop & TA090827E & 37.235 & 71.485 & 2264 & 10.0 & Layered silt to medium sand \\
\hline Khorog, south & TA090830C & 37.348 & 71.492 & 2152 & 29.3 & Layered fine to medium sand \\
\hline Khorog & TA090831A & 37.181 & 71.530 & 2108 & 72.0 & Cross-bedded fine to medium sand \\
\hline Rushan, south & TA110831N & 37.676 & 71.533 & 2059 & 10.7 & Layer of medium sand \\
\hline Rushan, south & TA1108310 & 37.676 & 71.533 & 2102 & 4.1 & Layer of coarse sand \\
\hline Vanj, confluence & TA090902C & 38.291 & 71.340 & 1589 & 84.6 & Cross-bedded fine to medium sand \\
\hline Khalaikhum, west & TA090908A & 38.124 & 70.493 & 1061 & 57.8 & Layer of fine to medium sand \\
\hline north-western Panj & TA090923B & 37.181 & 71.530 & 2108 & 72.0 & Cross-bedded medium to coarse sand \\
\hline Vakhsh river & TA090911A & 38.859 & 69.963 & 1115 & 21.2 & Layered medium sand \\
\hline Vakhsh river & TA090911B & 38.859 & 69.963 & 1115 & 21.2 & Cross-bedded medium sand \\
\hline
\end{tabular}

itude positioning, GNSS PPK ensures precise altitude determination with an uncertainty of $<5 \mathrm{~cm}$ (Table 1). The altitudes of the terrace surface, the sample site, and the modern river level were measured in order to calculate accurate terrace and sample heights above the river.

\subsection{OSL-based terrace dating}

\subsubsection{OSL sampling}

For each terrace we sampled the uppermost sand layer or lens to determine maximum ages of terrace abandonment and hence the earliest terrace incision age. Sample location within the uppermost fluvial layer kept a minimum distance of $50 \mathrm{~cm}$ below the terrace surface. Layer boundaries and areas of clear sediment inhomogeneities were avoided. OSL samples were taken after removing $\sim 50 \mathrm{~cm}$ of surface material to exclude the daylight-exposed part of the outcrop (Fig. 4A). Horizontal sediment cores were recovered in light-occluding cylinders and sealed for transport and storage. Sediment surrounding the hole made by the cylinder was sampled for gamma-spectrometric analysis of radionuclide content in order to determine the dose rate.

\subsubsection{Sample preparation}

Under subdued red light, an approximately $2 \mathrm{~cm}$-thick layer was removed from both ends of each sediment core. That material was used to measure the sediment's water content during the sampling season (in situ) and its maximum capacity (saturation). From the inner part of the sediment core, the coarse quartz fraction was separated by sieving (100-200 $\mu \mathrm{m})$, removal of carbonates ( $\mathrm{HCl} 10 \%$ ) and organic material $\left(\mathrm{H}_{2} \mathrm{O}_{2} 30 \%\right.$ ), feldspar flotation ( $\mathrm{HF}$ $0.2 \%, \mathrm{H}_{2} \mathrm{SO}_{4}$, dodecylamine, $\mathrm{HCl} 5 \%$ ), density separation (sodium polytungstate $2.62 \mathrm{~g} / \mathrm{cm}^{3}$ and $2.67 \mathrm{~g} / \mathrm{cm}^{3}$ ), etching (HF $40 \%, \mathrm{HCl} 37 \%)$, and further sieving $(90-160 \mu \mathrm{m})$. Homogeneous subsamples (aliquots) were prepared by fixing a monolayer of the extracted quartz grains on aluminum cups with silicon oil. Two aliquot sizes with diameters of $4 \mathrm{~mm}$ and $2 \mathrm{~mm}$ were used to address the effect of averaging the signals of multiple grain aliquots (Duller, 2008). However, $4 \mathrm{~mm}$ aliquots contain about 200-400 grains, of which only a few will be luminescent (e.g., Heer et al., 2012). The selection of aliquots suitable for quartz OSL measurements was based on negligible Infrared Stimulated Optical Luminescence (IRSL at $880 \mathrm{~nm}, 5 \mathrm{~s}$ ) signals. These signals highlight any feldspar contamination.

\subsubsection{OSL measurements}

OSL measurements were conducted using a Ris $\varnothing$ DA $20 \mathrm{OSL} / \mathrm{TL}$ reader equipped with a ${ }^{90} \mathrm{Sr}$ beta irradiator (5.6 Gy/min). The OSL emission was stimulated with blue LEDs $(470 \mathrm{~nm})$ for $50 \mathrm{~s}$ at $125^{\circ} \mathrm{C}$ and detected through a U 340 Hoya optical filter. Pre-heating (10s) before OSL stimulation eliminated unstable signal components. The temperature was selected after checking appropriate preheat conditions (pre-heat $200^{\circ} \mathrm{C}, 230^{\circ} \mathrm{C}, 260^{\circ} \mathrm{C}$; cut-heat $160{ }^{\circ} \mathrm{C}, 200^{\circ} \mathrm{C}, 230^{\circ} \mathrm{C}, 260^{\circ} \mathrm{C}$ ) for each sample. Additionally, the early background subtraction was tested as suggested by Cunningham and Wallinga (2010) to guarantee the signal estimation based on the fast signal component. Equivalent doses for each aliquot were determined using the single-aliquot regenerative-dose (SAR) protocol according to Murray and Wintle (2000). Subsequent to the natural signal, six regeneration cycles including the control of recuperation and recycling ratio assessed the aliquotspecific relationship between given dose and observed luminescence intensity. The control of sensitivity changes 


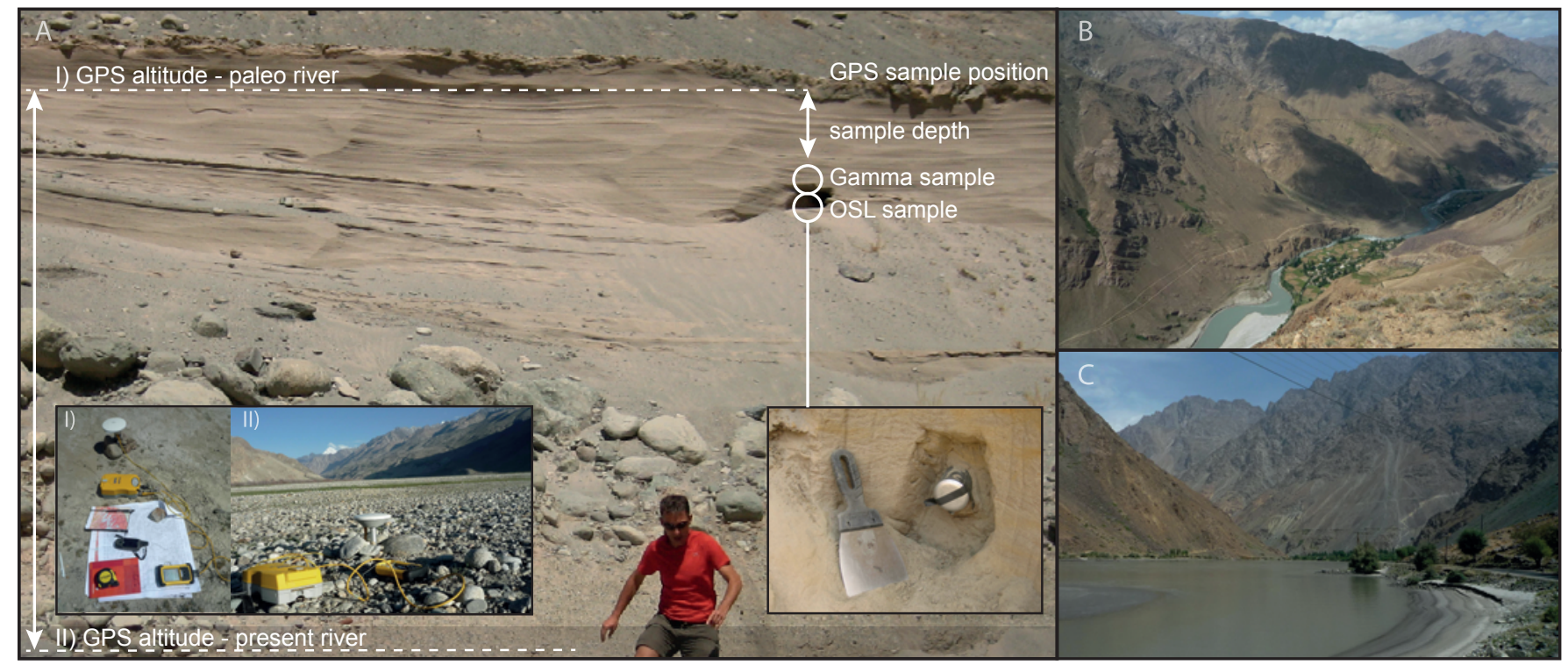

Figure 4: Terrace sampling for incision rate estimation. A: OSL sampling of the uppermost fluvial sand layer (minimum depth $50 \mathrm{~cm})$ and kinematic GPS measurements of terrace heights with I) terrace surface altitude and II) altitude of present river level. B: Steep valley formed by dominant incision with alluvial fans cut by the Panj and local modern beach sediments. C: Modern beach sediments illustrate local fluvial deposition.

involved test dose cycles after each OSL measurement cycle. Dose recovery tests were performed as described by Murray and Wintle (2003) in order to assess the reproducibility of an applied laboratory dose (recovery dose). The coefficient of variation $\left(\mathrm{v}_{D R}\right)$ describes the standard deviation of equivalent doses against the recovery dose. It indicates the adequacy of the used measurement procedure and enables the detection of unusual luminescence behavior of a sample under laboratory conditions (Murray and Wintle, 2003).

\subsubsection{Paleodose estimation}

Luminescence signals were examined for equivalent dose calculation using ANALYST v3.24 (Duller, 2007). In general, fluvial sediments are prone to insufficient light exposure before deposition. As a result sediments can comprise grains that have been bleached to different levels (e.g., Duller, 1994; Olley et al., 1998; Fuchs and Lang, 2001; Fuchs et al., 2005). Therefore, it is essential to analyze the distribution of equivalent doses for differential bleaching and to select appropriate statistical procedures for paleodose calculation. Calculations were performed using the programming language $\mathrm{R}$ and the Luminescence $\mathrm{R}$ package (Kreutzer et al., 2012).

Differential bleaching is assumed in the case of a nonlognormal distribution and/or high standard deviation (e.g., Galbraith et al., 1999). For these cases statistical modeling is required to determine the true burial age (e.g., Olley et al., 1998; Murray and Olley, 2002; Rodnight et al., 2006; Bailey and Arnold, 2006; Arnold et al., 2007). A widely used statistical approach to exclude incompletely bleached grains is the minimum age model (MAM) Galbraith et al. (1999). The MAM determines the paleodose from skewed data sets assuming well-bleached grains for the lower portion of the distribution. In the case of sediment mixing, the finite mixture model (FMM) may be utilized for unmixing the signal populations and deriving the dominant data cluster (Galbraith and Green, 1990).

Overdispersion is the essential input factor for MAM and FMM calculations. This takes into account additional data scatter that is not explained by individual measurement errors or incomplete bleaching. The Panj drainage basin does not provide suitable material (well bleached aeolian sand) to allow an independent overdispersion assessment. Arnold et al. (2007) and Arnold and Roberts (2009) found overdispersion values of 0.1-0.4 for fluvial deposits from various other study regions. We tested the influence of overdispersion between 0.05 and 0.5 on MAM results for all samples. There was no significant variation of paleodoses. Low effects of changing overdispersion resemble findings of Fuchs et al. (2013a) (supplementary data) for permafrost sediments of a high mountain setting in Switzerland. Best fit of the lowest data cluster (maximum in KDE estimates) was achieved for overdispersion values of $0.1-0.25$. These were consequently used for MAM calculations. Additionally, $2 \mathrm{~mm}$ aliquots were designed to improve the detection of the sufficiently bleached portion of equivalent doses in the observed dose distribution. The lower number of grains per aliquot reduces the averaging effect of individual signals and therefore the risk of grains with residual components masking well-bleached grains (e.g., Murray and Olley, 2002; Duller, 2008; Cun- 
ningham et al., 2011).

\subsubsection{Dose rate estimation}

Dose rate was estimated by measuring the specific activity of radionuclides (decay chains of ${ }^{238} \mathrm{U},{ }^{232} \mathrm{Th}$ and ${ }^{40} \mathrm{~K}$ ) in each sample, utilizing low-level HPG (high-purity germanium) gamma spectrometry. Radioactive disequilibria in the ${ }^{238} \mathrm{U}$ series were identified by comparing the specific activities of subsequent nuclides, particularly ${ }^{222} \mathrm{Rn}$ daughter products to monitor potential Rn-loss (e.g., Krbetschek et al., 1994; Aitken, 1998; Kulig, 2005; Li et al., 2008). The cosmic dose rate was estimated according to the coordinates and altitude of the sample and the thickness of the sediment cover. The efficiency of the total dose rate was corrected according to the density of quartz and paleowater content for each sample (e.g., Aitken, 1998; Li et al., 2008). To estimate the paleowater content, we used the in situ water content values, and the results from water saturation analyses as a reference for seasonal and past variations in the water content. The generally dry conditions of the inner continental climate of the study area and the short water retention times of sandy sediment imply the predominance of low contents of paleowater, comparable to the measured in situ water content. An error of $10 \%$ is included to account for seasonal and site-related paleovariations of the water content. All parameters for calculating the effective total dose rate were processed together with the estimated paleodoses for OSL age determination using ADELE software (Kulig, 2005).

\subsection{Incision rate estimation}

Derived OSL ages represent the age of the latest deposition of fluvial sand and therefore, maximum ages of terrace abandonment. The clear layering of the well-sorted sand, intercalated with pebble units, indicates that the fluvial transport capacity underwent rapid changes. Given the dynamic fluvial environment, we consider the OSL ages as close estimates of the onset of incision. Dividing the relative terrace heights above the present river by the OSL terrace age returns mean incision rates over the dated time range. Uncertainties of incision rates are calculated based on uncertainties of terrace height estimates, discrepancies in heights between the sampled sand layer and terrace surface, and for errors in the OSL ages.

\subsection{Hack Index estimation}

Calculated incision rates can only represent the response of the river at the location of the sampled terrace. To reveal the regional context of the local incision rates, we use the longitudinal profile of the Panj river and the Hack Index (Hack, 1973) and compare results to valley shape ratios (VSR; Burbank and Anderson, 2001; Fuchs et al., 2013b). The longitudinal profile reveals the stage the modern river has reached in eroding towards the base level. Under steady state conditions, the profile can be represented by a logarithmic function of altitude and distance from the source, with constant stream power along the course of the river (Hack, 1957, 1973). Deviations of the actual profile from the equilibrated river profile indicate the zones of changing controlling factors and/or stages of river adjustment (Hack, 1957, 1973; Pazzaglia et al., 1998; Snyder et al., 2000; Burbank and Anderson, 2001; Demoulin, 2011).

The Hack Index is useful for locating and quantifying divergences from a non-perturbed river profile by relating the slope of a reach to the length of the upstream river (e.g., Hack, 1973; Burbank and Anderson, 2001; Shahzad and Gloaguen, 2011b). Tectonic forcing can be inferred when convexities in the river profile do not correlate with lithologic contrasts and/or hydrological changes such as confluences with major tributaries (e.g., Hack, 1973; Demoulin, 1998, 2011; Burbank and Anderson, 2001). The extraction of the longitudinal river profile was carried out using the MATLAB based toolbox TecDEM (Shahzad and Gloaguen, 2011a,b) and a digital elevation model (ASTER GDEM, resolution $30 \mathrm{~m}$ ). The Hack Index has been calculated for altitude intervals of $100 \mathrm{~m}$ along the extracted Panj profile. To reduce the effects of artifacts, we filtered out values where stream elevation was wrongly shown to increase downstream (carving) and smoothed the elevation data using a moving window of $300 \mathrm{~m}$ prior to Hack Index calculation.

\section{Results}

\subsection{Dose rate estimates}

Gamma spectrometric measurements revealed a trend of lower specific activities for ${ }^{238} \mathrm{U}$ and ${ }^{232} \mathrm{Th}$ downstream of the town of Khorog (TA31A-23B) and higher values upstream of Khorog (Table 2 ). No radioactive disequilibrium was detected. The specific activity ${ }^{40} \mathrm{~K}$ is high $(>10$ times compared to ${ }^{238} \mathrm{U}$ or ${ }^{232} \mathrm{Th}$ ) in most samples. The lowest contents of radionuclides in the sediment were determined in the terrace of the Vakhsh River (TA11A and B). Terrace altitudes and sediment cover imply that cosmic dose rates range between $154 \mathrm{mGy} / \mathrm{kyr}$ and $309 \mathrm{mGy} / \mathrm{kyr}$. The in situ water contents of $0.1 \%$ to $3.7 \%$ of the sample weight reflect the dry summer sampling conditions. Saturation values of $26.4 \%$ to $46.1 \%$ allow the potential for higher paleowater content than measured but terrace heights above the modern river $(>4 \mathrm{~m})$ and grain sizes of sampled sand units are assumed to limit such levels of saturation to short time intervals.

\subsection{OSL signal characteristics}

In general, the decay of the luminescence signals is slightly delayed in shine down curves but signal intensities are significant compared to the background level (BG) (Fig. 5, left). Early BG subtraction was not appropriate for the investigated samples as the very low remaining initial OSL signal (first second) resulted in higher curve fit errors. For most samples, low pre-heat temperatures $\left(160^{\circ} \mathrm{C}\right.$ to $200^{\circ} \mathrm{C}$ ) and raised test doses yielded reliable equivalent 
Table 2: Parameters for dose rate estimation: sediment-related dose rate (radionuclides ${ }^{238} \mathrm{U},{ }^{232} \mathrm{Th},{ }^{40} \mathrm{~K}$, sediment cover, water content) and cosmic dose rate ( cosmD). Bold letters in sample names indicate notations used in the text.

\begin{tabular}{|c|c|c|c|c|c|c|c|}
\hline Sample & $\begin{array}{l}\text { Sedin } \\
\text { cover } \\
{[\mathrm{cm}]} \\
\end{array}$ & $\begin{array}{l}\text { ent } \\
\text { wate } \\
\text { in situ }[\%]\end{array}$ & $\begin{array}{l}\text { content } \\
\text { saturation [\%] }\end{array}$ & $\begin{array}{r}{ }^{238} \mathrm{U} \\
{[\mathrm{Bq} / \mathrm{kg}]}\end{array}$ & $\begin{array}{l}{ }^{232} \mathrm{Th} \\
{[\mathrm{Bq} / \mathrm{kg}]}\end{array}$ & $\begin{array}{r}{ }^{40} \mathrm{~K} \\
{[\mathrm{~Bq} / \mathrm{kg}]}\end{array}$ & $\begin{array}{r}\text { cosmD } \\
{[\mathrm{mGy} / \mathrm{kyr}]}\end{array}$ \\
\hline TA090826A & 50 & 0.2 & 26.4 & $69.1 \pm 1.1$ & $83.4 \pm 3.3$ & $1035.3 \pm 9.1$ & 302 \\
\hline TA090826C & 50 & 0.2 & 33.8 & $47.2 \pm 0.8$ & $67.4 \pm 2.7$ & $780.6 \pm 6.8$ & 301 \\
\hline TA090825A & 100 & 0.1 & 33.5 & $48.7 \pm 0.8$ & $92.7 \pm 3.7$ & $723.3 \pm 6.2$ & 308 \\
\hline TA090825B & 100 & 0.2 & 30.9 & $59.2 \pm 0.9$ & $111.1 \pm 4.4$ & $1029.2 \pm 9.1$ & 299 \\
\hline TA100906A & 500 & 2.4 & 29.9 & $50.1 \pm 0.8$ & $63.4 \pm 2.5$ & $700.5 \pm 6.5$ & 172 \\
\hline TA090827H & 100 & 0.8 & 30.9 & $84.7 \pm 1.4$ & $101.8 \pm 4.0$ & $1226.3 \pm 10.6$ & 275 \\
\hline TA090828B & 50 & 0.9 & 44.2 & $55.3 \pm 0.9$ & $66.4 \pm 2.6$ & $854.9 \pm 7.8$ & 291 \\
\hline TA090828D & 50 & 1.3 & 29.4 & $89.8 \pm 1.4$ & $126.5 \pm 5.0$ & $1170.9 \pm 10.3$ & 291 \\
\hline TA090827E & 100 & 1.6 & 41.7 & $60.2 \pm 1.0$ & $50.3 \pm 2.0$ & $1194.9 \pm 10.1$ & 272 \\
\hline TA090830C & 100 & 3.2 & 46.1 & $55.9 \pm 0.9$ & $64.8 \pm 2.6$ & $855.9 \pm 7.8$ & 269 \\
\hline TA090831A & 200 & 1.4 & 33.1 & $31.7 \pm 0.5$ & $32.4 \pm 1.3$ & $1299.5 \pm 11.2$ & 236 \\
\hline TA110831N & 80 & 1.3 & 31.6 & $70.6 \pm 3.0$ & $91.9 \pm 3.6$ & $1325.4 \pm 11.5$ & 268 \\
\hline TA1108310 & 100 & 0.9 & 29.3 & $54.1 \pm 0.9$ & $59.1 \pm 2.3$ & $1288.3 \pm 10.8$ & 258 \\
\hline TA090902C & 100 & 1.5 & 32.1 & $39.3 \pm 0.6$ & $64.1 \pm 2.5$ & $1048.0 \pm 8.7$ & 241 \\
\hline TA090908A & 50 & 2.4 & 35.2 & $43.7 \pm 0.7$ & $58.6 \pm 2.3$ & $1036.0 \pm 9.2$ & 233 \\
\hline TA090923B & 50 & 2.5 & 33.5 & $28.4 \pm 0.5$ & $36.3 \pm 1.4$ & $581.2 \pm 5.5$ & 225 \\
\hline TA090911A & 50 & 3.7 & 31.7 & $25.0 \pm 0.4$ & $28.9 \pm 1.1$ & $623.1 \pm 5.6$ & 236 \\
\hline TA090911B & 400 & 2.2 & 27.4 & $29.8 \pm 0.5$ & $29.6 \pm 1.2$ & $584.2 \pm 5.5$ & 154 \\
\hline
\end{tabular}

Table 3: Results of OSL paleodose estimation for $4 \mathrm{~mm}$ and $2 \mathrm{~mm}$ aliquots using the arithmetic mean and the MAM ( $\mathrm{D}_{e}$ : equivalent dose, MAM3: three parameter minimum age model (Galbraith et al. 1999), N: number of aliquots, sd: standard deviation, $\mathrm{v}_{D R}$ : coefficient of variation giving the deviation from the recovery dose in percent of the recovery dose, $\mathrm{P}_{D}$ : paleodose, bold values: used for age calculation. Bold letters in sample names indicate notations used in the text.

\begin{tabular}{|c|c|c|c|c|c|c|c|c|c|}
\hline \multirow[t]{2}{*}{ Sample } & \multicolumn{4}{|c|}{$\mathrm{D}_{e}(4 \mathrm{~mm})$} & MAM3 & \multicolumn{3}{|c|}{$\mathrm{D}_{e}(\mathbf{2} \mathrm{mm})$} & \multirow[b]{2}{*}{$\begin{array}{l}\mathrm{v}_{D R} \\
{[\%]}\end{array}$} \\
\hline & $\mathrm{N}$ & $\begin{array}{l}\text { mean } \\
{[\mathrm{Gy}]}\end{array}$ & $\begin{array}{r}\text { sd } \\
{[\%]}\end{array}$ & $\begin{array}{l}\mathrm{v}_{D R} \\
{[\%]}\end{array}$ & $\begin{array}{l}\mathrm{P}_{D} \\
\quad[\mathrm{~Gy}]\end{array}$ & $\mathrm{N}$ & $\begin{array}{l}\text { mean } \\
{[\mathrm{Gy}]}\end{array}$ & $\begin{array}{r}\mathrm{sd} \\
{[\%]}\end{array}$ & \\
\hline TA090826A & 32 & $30.7 \pm 1.8$ & 33.5 & 5.7 & $28.2 \pm 2.3$ & 12 & $32.8 \pm 3.5$ & 37.3 & 27.0 \\
\hline TA090826C & 59 & $100.7 \pm 5.1$ & 38.9 & 10.7 & $67.2 \pm 7.4$ & 15 & $71.3 \pm 10.9$ & 59.0 & 44.5 \\
\hline TA090825A & 4 & $142.1 \pm 3.0$ & 4.2 & - & 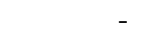 & 10 & $108.3 \pm 5.0$ & 14.5 & - \\
\hline TA090825B & 49 & $88.6 \pm 2.8$ & 22.3 & 5.4 & $69.3 \pm 4.0$ & 19 & $80.5 \pm 3.0$ & 16.1 & 12.2 \\
\hline TA100906A & 57 & $118.9 \pm 4.3$ & 27.4 & 7.4 & $85.8 \pm 6.1$ & - & - & - & - \\
\hline TA090827H & 27 & $35.4 \pm 2.5$ & 36.2 & 11.8 & $20.2 \pm 3.1$ & 20 & $28.5 \pm 2.6$ & 41.1 & 26.8 \\
\hline TA090828B & 39 & $4.8 \pm 0.3$ & 41.3 & 11.1 & $3.1 \pm 0.3$ & 11 & $5.4 \pm 0.7$ & 41.8 & 6.8 \\
\hline TA090828D & 58 & $24.6 \pm 1.4$ & 41.7 & 9.5 & $15.9 \pm 1.8$ & 18 & $22.9 \pm 2.9$ & 54.1 & 9.7 \\
\hline TA090827E & 61 & $16.5 \pm 1.0$ & 47.9 & 18.8 & $7.8 \pm 0.7$ & - & & - & - \\
\hline TA090830C & 40 & $23.5 \pm 1.1$ & 28.2 & 11.2 & $18.3 \pm 1.6$ & 15 & $14.1 \pm 0.9$ & 25.5 & 17.3 \\
\hline TA090831A & 50 & $94.6 \pm 5.5$ & 38.6 & 17.5 & $62.6 \pm 8.3$ & 13 & $64.3 \pm 8.2$ & 46.1 & 21.9 \\
\hline $\mathbf{T A} 110831 \mathbf{N}^{a}$ & 33 & $17.9 \pm 1.4$ & 45.3 & 11.5 & $17.7 \pm 1.3$ & - & - & - & - \\
\hline TA1108310 & 55 & $17.9 \pm 1.7$ & 69.1 & 10.6 & $12.9 \pm 0.9$ & - & - & - & - \\
\hline TA090902C & 38 & $137.8 \pm 6.7$ & 30.1 & 10.2 & $96.2 \pm 9.9$ & 12 & $105.5 \pm 14.0$ & 46.0 & 34.5 \\
\hline TA090908A & 26 & $68.7 \pm 3.7$ & 27.5 & 6.7 & $45.3 \pm 5.1$ & 20 & $62.3 \pm 3.6$ & 25.5 & 11.8 \\
\hline TA090923B & 39 & $77.9 \pm 2.6$ & 21.1 & 6.7 & $69.6 \pm 3.7$ & 17 & $72.3 \pm 5.2$ & 29.8 & 6.5 \\
\hline TA090911A & 20 & $21.6 \pm 1.1$ & 22.3 & 6.2 & $18.2 \pm 1.6$ & 20 & $21.2 \pm 1.0$ & 21.5 & 7.2 \\
\hline TA090911B & 20 & $28.1 \pm 0.7$ & 11.1 & 6.4 & $25.1 \pm 2.1$ & 19 & $25.1 \pm 1.3$ & 22.1 & 9.4 \\
\hline
\end{tabular}

\footnotetext{
${ }^{a}$ instead of MAM3, the finite mixture model (FMM; Galbraith and Green 1990) is used to calculate the paleodose of the sample)
} 

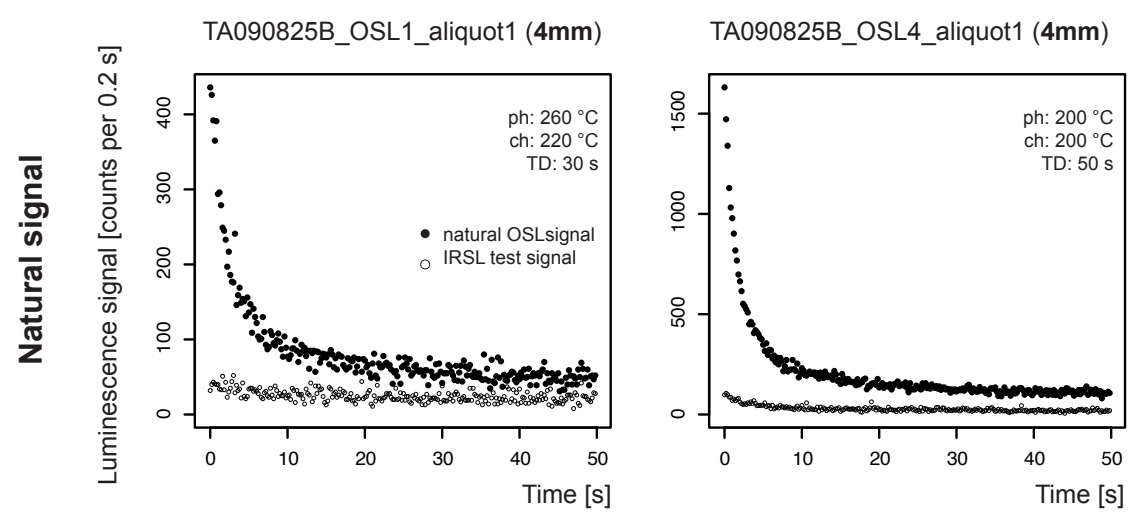

TA090825B_OSL5_aliquot2 (2mm)
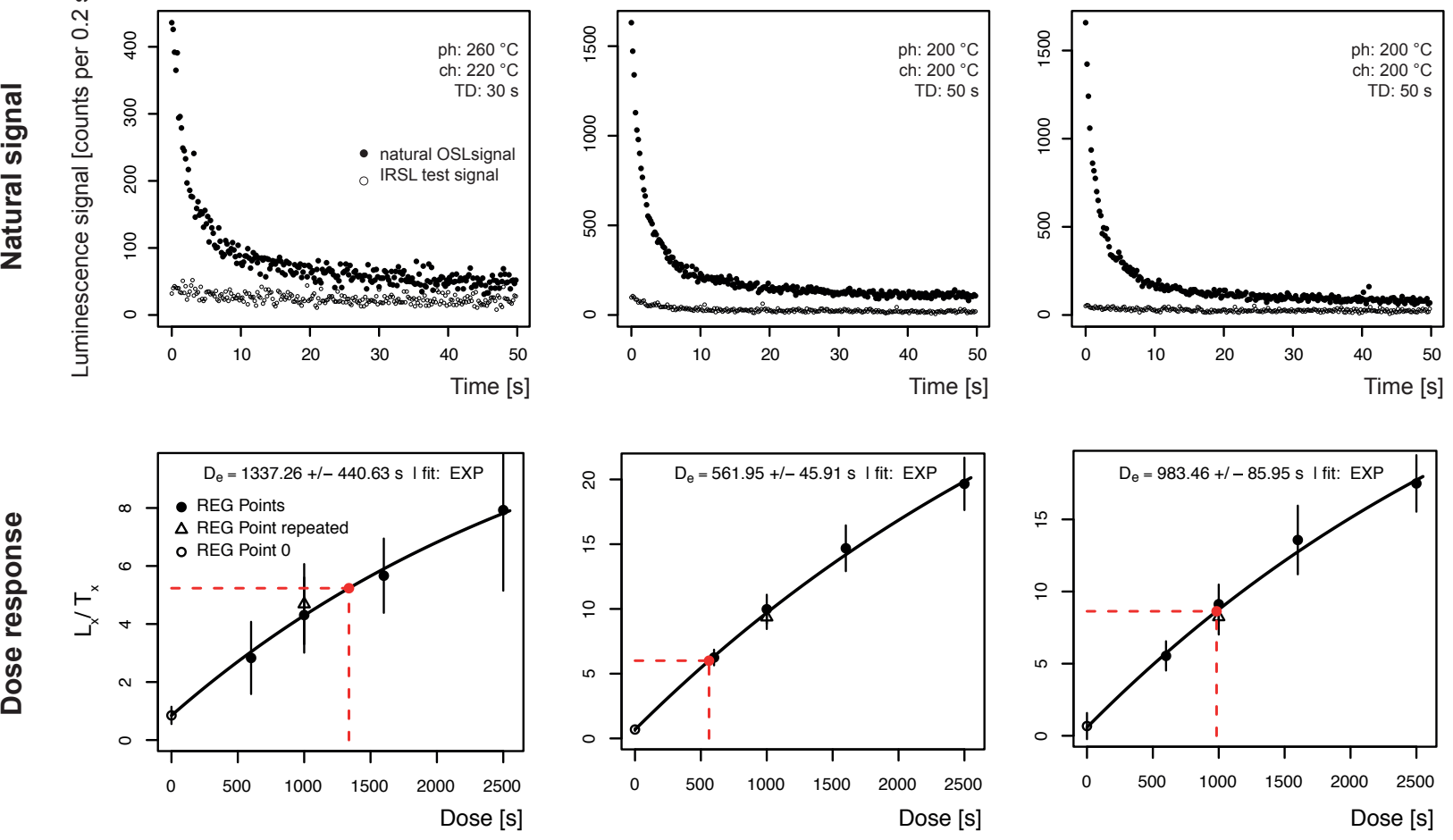

Figure 5: OSL signal characteristics. Results of $4 \mathrm{~mm}$ and $2 \mathrm{~mm}$ aliquots measured before and after adjusting the single-aliquot regenerativedose (SAR) protocol parameters pre-heat, cut-heat and test dose from sample TA25B (left: shine down curve of natural signal, right: dose response curve, ph: pre-heat temperature, ch: cut-heat temperature, TD: test dose).

dose estimates (Fig. 5, right) and a reproducibility of $\mathrm{v}_{D R}$ $5 \%$ to $12 \%$ (Table 3 ). Only two samples show a low reproducibility with $\mathrm{v}_{D R}$ of $17 \%$ to $19 \%$ (TA27E and $31 \mathrm{~A}$ ).

Figure 6 (left) illustrates how lower equivalent dose errors and standard deviations were measured when using low temperatures and a higher a test dose (compare OSL1, OSL3 and OSL4 of TA25B, Fig. 6, top left). Low signal intensities increased dose response uncertainties for the $2 \mathrm{~mm}$ aliquots (Fig. 5, bottom) that was problematic especially for young samples. The $2 \mathrm{~mm}$ aliquots of TA27E yielded no equivalent dose due to inconsistent luminescence properties. The lower reproducibility in dose recovery tests of $2 \mathrm{~mm}$ aliquots (Table 3 ) did not allow for an improved detection of inhomogeneous bleaching. To allow direct comparisons paleodose was estimated on all samples using $4 \mathrm{~mm}$ aliquots. Sample TA25A was an exception due to limited material and so $2 \mathrm{~mm}$ aliquots had to be used. In this case, an overestimation of the age is possible as residual signals are not detectable or accounted for.

The dose distributions of all samples indicate differential bleaching. Standard deviations between $20 \%$ and $40 \%$ exceed the material-related variation $\left(\mathrm{v}_{D R}\right)$ by $10 \%$ to $20 \%$ (Table 3). For samples TA27E and TA31A, the low reproducibility of $\mathrm{v}_{D R}>15 \%$ masks any indication of differential bleaching. However, the skewed distributions show arithmetic means above the median. Both parame- ters clearly overestimate the main data cluster indicated by the maximum kernel density estimates (cf. PDF in Fig. 6, right). To address the skewness in dose distributions, we apply the minimum age model, MAM (Galbraith et al., 1999).

\subsection{OSL-based terrace ages}

The OSL dating reveals maximum ages of terrace abandonment between $(23.0 \pm 2.9) \mathrm{kyr}$ and $(0.6 \pm 0.1) \mathrm{kyr}$ (Table 4). OSL age uncertainties range from $12 \%$ to $20 \%$. The oldest terraces cluster with overlapping errors between $23.0 \mathrm{kyr}$ and $19.0 \mathrm{kyr}$ with an uncertainty of $\pm 2.9 \mathrm{kyr}$. This oldest generation is represented by four terraces between $191.0 \mathrm{~m}$ and $84.6 \mathrm{~m}$ in height above the modern river level (a.r.l.; Table 4). Four samples of the Panj river terraces are dated between $14.8 \mathrm{kyr}$ and $9.1 \mathrm{kyr}$. Regarding the OSL age uncertainties, the age cluster overlaps with ages from older terraces but not with the ages of younger terraces along the Panj. Terrace heights range from $72.0 \mathrm{~m}$ a.r.l. to $57.8 \mathrm{~m}$ a.r.l., with the exception of one considerably lower terrace (TA26C: $24.9 \mathrm{~m}$ a.r.l.). The terraces older than $9 \mathrm{kyr}$ are located at the southern and northern rim of the Shakhdara Dome and downstream of the Yazgulom Dome. The youngest terraces are found at the northern part of the Panj where it crosses the Shakhdara Dome and 

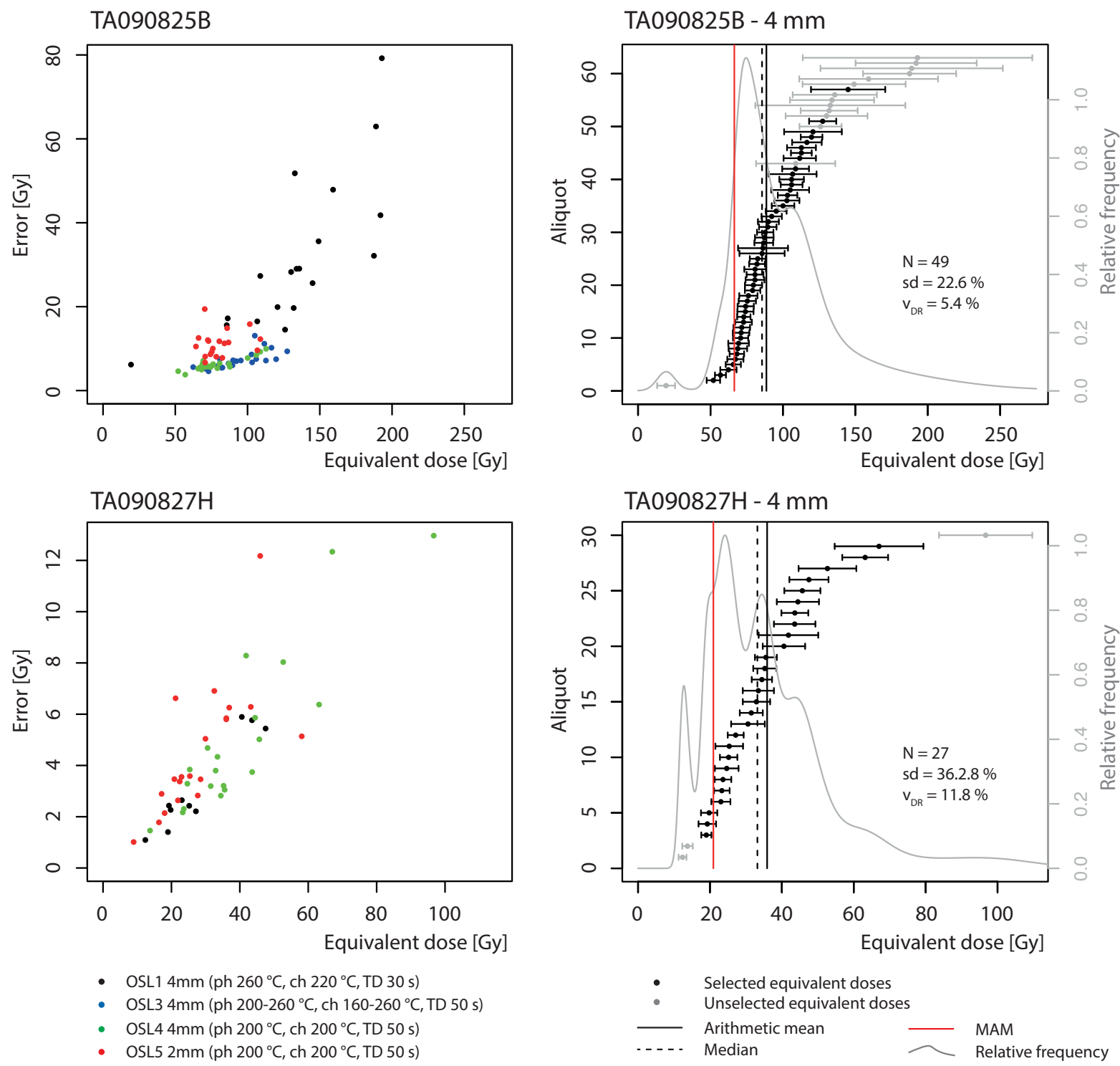

Figure 6: Characteristics of equivalent dose distributions. Left: Comparison of applied measurement condition. Right: Statistical analyses of $4 \mathrm{~mm}$ aliquots for paleodose estimation $\left(\mathrm{N}\right.$ : number of equivalent doses, sd: standard deviation, $\mathrm{v}_{D R}$ : coefficient of variation from dose recovery tests, ph: pre-heat temperature, ch: cut heat temperature, TD: test dose, PDF: probability density function, MAM: paleodose based on minimum age model).

further downstream before the confluence with the Bartang River from where six sampled terraces yielded OSL ages $<5 \mathrm{kyr}$ with a maximum uncertainty of $\pm 0.7 \mathrm{kyr}$. Although most of the young terraces have ages between $2 \mathrm{kyr}$ and $3 \mathrm{kyr}$, terrace heights vary considerably from $20 \mathrm{~m}$ to only $4 \mathrm{~m}$. Two samples from the Vakhsh river date sand units of the same terrace from $0.5 \mathrm{~m}$ and $4.0 \mathrm{~m}$ below the surface. Using their age difference of $2.6 \mathrm{kyr}$ a mean sedimentation rate of $1.35 \mathrm{~m} / \mathrm{kyr}$ could be inferred. The terrace surface $(\sim 50 \mathrm{~cm}$ above sample TA11A) is estimated to be $5.9 \mathrm{kyr}$ old, older than Panj terraces of comparable elevation above the modern river. However, age uncertainties overlap and, hence, could also be interpreted as fast deposition of the entire uppermost fluvial layer of the terrace during $7.2-7.4 \mathrm{kyr}$. An average value $(7.3 \pm 1.5) \mathrm{kyr}$ was used for comparisons.

\subsection{Panj incision rates}

The relationship between OSL ages and terrace heights is illustrated in Fig. 7. Our data show OSL age clusters that may evidence three phases of terrace sedimentation along the Panj. However, terrace heights are different for terraces of similar age. The resulting incision rates are therefore variable and range from $(1.7 \pm 0.3) \mathrm{mm} / \mathrm{yr}$ to $(10.0 \pm 2.0) \mathrm{mm} / \mathrm{yr}$, independent of their association with one of the indicated age clusters. The solid black line 
Table 4: OSL-based terrace ages and corresponding incision rates averaging over the time since deposition of the uppermost fluvial sand $\left(\mathrm{P}_{D}\right.$ : paleodose, D: dose rate, $\mathrm{m}$ a.r.l.: meter above river level.

\begin{tabular}{|c|c|c|c|c|c|c|}
\hline Sample & $\begin{array}{l}\mathbf{P}_{D} \\
{[\mathrm{~Gy}]} \\
\end{array}$ & $\begin{array}{c}\mathbf{D} \\
\text { total } \\
{[\mathrm{mGy} / \mathrm{yr}]} \\
\end{array}$ & $\begin{array}{c}\text { OSL age } \\
{[\mathrm{kyr}]}\end{array}$ & $\begin{array}{c}\text { Terrace } \\
\text { height } \\
\text { [m a.r.l. }]\end{array}$ & $\begin{array}{r}\text { Incision rate } \\
{[\mathrm{mm} / \mathrm{yr}]}\end{array}$ & \\
\hline TA090826A & $28.2 \pm 2.3$ & $5.9 \pm 1.0$ & $4.7 \pm 0.7$ & $13.0 \pm 0.8$ & $2.7 \pm 0.6$ & \\
\hline TA090826C & $67.2 \pm 7.4$ & $4.5 \pm 0.7$ & $14.8 \pm 2.4$ & $24.9 \pm 0.3$ & $1.7 \pm 0.3$ & \\
\hline TA090825A & $108.3 \pm 5.0$ & $4.8 \pm 0.8$ & $22.6 \pm 2.8$ & $191.0 \pm 2.5$ & $8.4 \pm 1.2$ & \\
\hline TA090825B & $69.3 \pm 4.0$ & $6.2 \pm 1.0$ & $11.2 \pm 1.4$ & $68.0 \pm 2.5$ & $6.1 \pm 1.1$ & \\
\hline TA $100906 \mathbf{A}$ & $85.8 \pm 6.1$ & $3.9 \pm 0.4$ & $22.1 \pm 2.9$ & $151.0 \pm 2.6$ & $6.8 \pm 1.0$ & \\
\hline TA090827H & $20.2 \pm 3.1$ & $7.0 \pm 1.2$ & $2.8 \pm 0.5$ & $20.7 \pm 0.1$ & $7.3 \pm 1.6$ & \\
\hline TA090828B & $3.1 \pm 0.3$ & $4.9 \pm 0.8$ & $0.6 \pm 0.1$ & $6.3 \pm 0.1$ & $10.0 \pm 2.0$ & \\
\hline TA090828D & $15.9 \pm 1.8$ & $7.4 \pm 1.2$ & $2.2 \pm 0.3$ & $15.3 \pm 0.1$ & $7.1 \pm 1.3$ & \\
\hline TA090827E & $7.8 \pm 0.7$ & $5.7 \pm 0.9$ & $1.4 \pm 0.2$ & $10.0 \pm 0.5$ & $7.3 \pm 2.2$ & \\
\hline TA090830C & $18.3 \pm 1.6$ & $4.7 \pm 0.8$ & $3.9 \pm 0.7$ & $29.3 \pm 0.1$ & $7.6 \pm 1.6$ & \\
\hline TA090831A & $62.6 \pm 8.3$ & $5.2 \pm 0.9$ & $12.1 \pm 2.1$ & $72.0 \pm 0.1$ & $5.9 \pm 1.1$ & \\
\hline TA110831N & $17.7 \pm 1.3$ & $6.5 \pm 1.1$ & $2.7 \pm 0.4$ & $10.7 \pm 0.5$ & $3.9 \pm 0.7$ & \\
\hline TA1108310 & $12.9 \pm 0.9$ & $5.6 \pm 0.6$ & $2.3 \pm 0.3$ & $4.1 \pm 0.6$ & $1.8 \pm 0.5$ & \\
\hline TA090902C & $96.2 \pm 9.9$ & $5.1 \pm 0.5$ & $19.0 \pm 2.9$ & $84.6 \pm 0.1$ & $4.5 \pm 0.7$ & \\
\hline TA090908A & $45.3 \pm 5.1$ & $5.0 \pm 0.5$ & $9.1 \pm 1.6$ & $57.8 \pm 0.1$ & $6.3 \pm 1.1$ & \\
\hline TA090923B & $69.6 \pm 3.7$ & $3.0 \pm 0.3$ & $23.0 \pm 2.9$ & $89.0 \pm 2.5$ & $3.9 \pm 0.6$ & \\
\hline TA090911A & $18.2 \pm 1.6$ & $2.9 \pm 0.5$ & $6.2 \pm 1.2$ & $21.2 \pm 0.1$ & $3.6 \pm 0.7$ & $a$ \\
\hline TA090911B & $25.1 \pm 2.1$ & $2.9 \pm 0.3$ & $8.8 \pm 1.6$ & $21.2 \pm 0.1$ & $2.9 \pm 0.6$ & $b$ \\
\hline
\end{tabular}

$a$ incision rate estimation based on terrace surface age of $(5.9 \pm 1.1)$ kyr inferred from the age and depth difference between the samples TA090911A and 11B from the same terrace of $350 \mathrm{~cm}$ and $2.6 \mathrm{kyr}$ yielding a sedimentation rate of $\sim 50 \mathrm{~cm}$ per $0.4 \mathrm{kyr}$ )

$b$ incision rate estimation based on terrace surface age of $(7.3 \pm 1.5)$ kyr inferred from both samples from the same terrace with overlapping age errors of and assuming a fast deposition of the entire uppermost sand layer of the terrace

in Fig. 7 represents the linear regression for all investigated terraces (sample TA25A is not included because of differing paleodose estimation). An overall incision rate of $5.6 \mathrm{~mm} / \mathrm{yr}$ is determined for the Panj. Deviations from the average incision rate (Table 4 ) at specific localities show no link to terrace ages. This suggests that local control factors have influenced the pattern of fluvial incision as opposed to temporal variation.

Values above the main regression line represent terraces that are located where the northward-deflected Panj cuts across the Shakhdara Dome and in the northern Panj, upstream (east) of the DFZ. Linear regression for all samples from the Shakhdara zone indicates a strong correlation between OSL ages and terrace heights, suggesting relatively constant incision over timescales of $10^{3} \mathrm{yr}$ to $10^{4} \mathrm{yr}$ with a mean rate of $7.3 \mathrm{~mm} / \mathrm{yr}$. In the north-central Shakhdara section, high incision rates of $(7.1 \pm 1.3) \mathrm{mm} / \mathrm{yr}$ to $(10.0 \pm 2.0) \mathrm{mm} / \mathrm{yr}$ are based solely on terraces younger than 5 kyr. Older terraces close to the northern and southern dome boundaries indicate that high incision rates of $(5.9 \pm 1.1) \mathrm{mm} / \mathrm{yr}$ to $(8.4 \pm 1.2) \mathrm{mm} / \mathrm{yr}$ have persisted over the last $\sim 25 \mathrm{kyr}$. The sample TA08A east of the DFZ yielded the only incision rate $(6.3 \pm 1.1) \mathrm{mm} / \mathrm{yr}$ above the main regression line outside of the Shakhdara section.

Values below the regression line show variable incision rates between $(1.7 \pm 0.3) \mathrm{mm} / \mathrm{yr}$ and $(4.5 \pm 0.7) \mathrm{mm} / \mathrm{yr}$. How ever, terraces north of the Shakhdara Dome (downstream of the confluence with the Gunt and Shakhdara rivers and further north, where the Panj turns to flow towards the northwest and west) also indicate a good correlation be- tween OSL ages and terrace heights. The incision rates of the two youngest terraces range from $1.8 \mathrm{~mm} / \mathrm{yr}$ to 3.9 $\mathrm{mm} / \mathrm{yr}$. These are located between the confluences with the Gunt and Shakhdara rivers and the southern rim of the Yazgulom Dome. The two 23-19 kyr old terraces north of the Yazgulom Dome and further downstream show slightly higher incision rates of $3.9-4.5 \mathrm{~mm} / \mathrm{yr}$ (Table 4 ). The latter rates are similar to estimates from the Vakhsh River terrace that joins the Panj further downstream. Using the terrace surface age of $\sim 5.9 \mathrm{kyr}$ (cf. footnotes in Table 4 , an incision rate of $(3.6 \pm 0.7) \mathrm{mm} / \mathrm{yr}$ is calculated. Regarding the overlapping errors of both ages, and assuming a terrace age of $7.3 \mathrm{kyr}$, the incision rate is $(2.9 \pm 0.6) \mathrm{mm} / \mathrm{yr}$.

The lowest incision rates were determined for Panj terraces immediately upstream of where the river starts cutting through the Shakhdara Dome. Two terraces yielded incision rates of $(1.7 \pm 0.3) \mathrm{mm} / \mathrm{yr}$ and $(2.7 \pm 0.6) \mathrm{mm} / \mathrm{yr}$. Two nearby terraces yielded much higher incision rates (cf. TA25A and B compared to TA26A and $\mathrm{C}$ with $\sim 5 \mathrm{~mm} / \mathrm{yr}$, see Table 4). The contrast is especially apparent when comparing the low incision rate of sample TA26C to the similarly-aged sample TA25B from a separate terrace. The same applies to the $<5$ kyr old sample TA26A when compared to samples from terraces of similar age from the north-central Shakhdara zone (e.g. TA30C, Fig. 7). The strongest contrasts in incision rates coincide with the southernmost deflection of the Panj, where the river crosses the SPSZ, and for terraces south and north of the GSZ. 


\section{OSLage versus terrace heights}

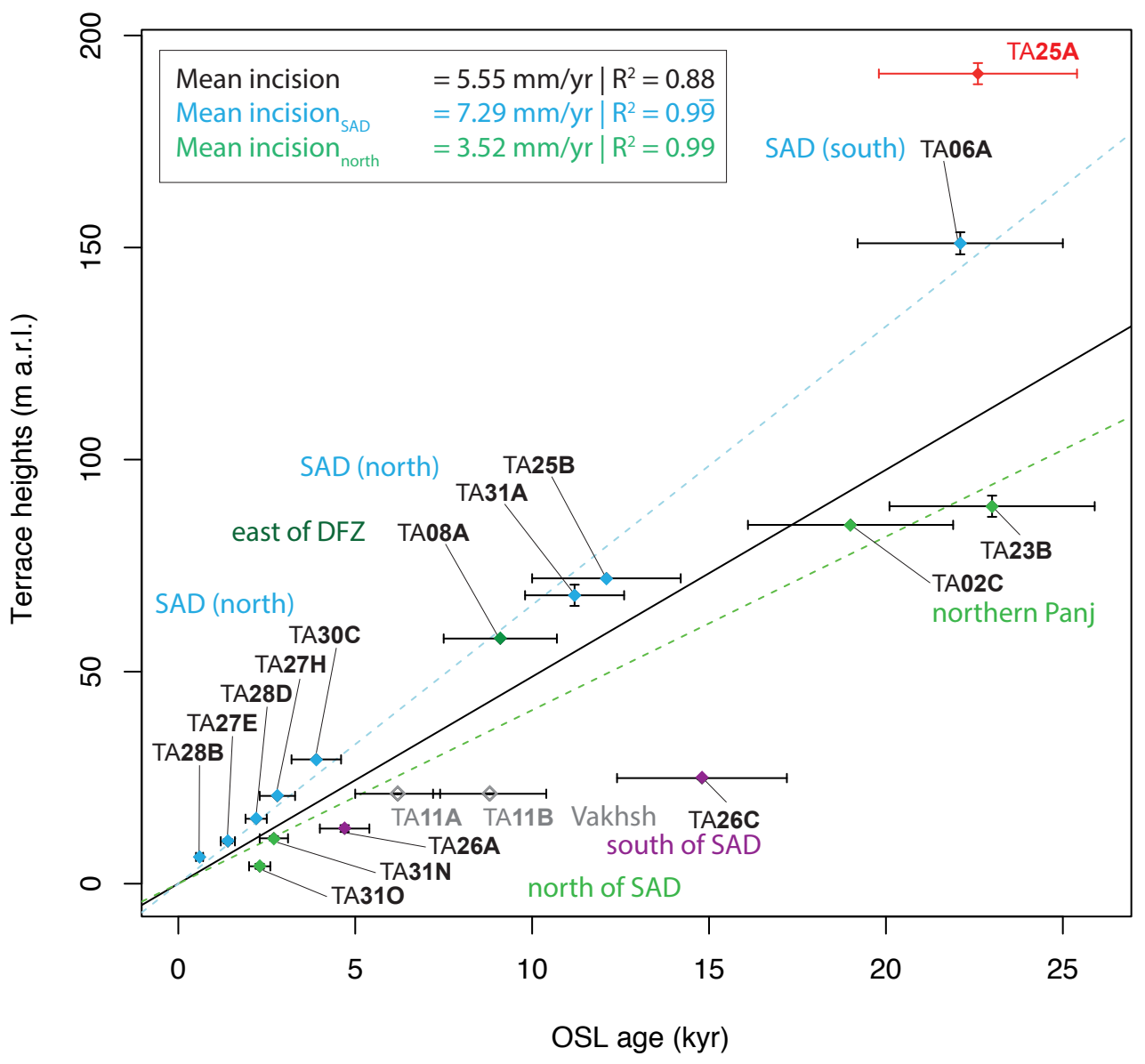

Figure 7: Correlation between OSL ages and terrace heights. Indication of location-related incision rates along the Panj. Similar depositional ages are derived from terraces with varying heights above the modern Panj (solid black line: linear regression of all sampled terraces excluding TA090825A, blue dotted line: linear regression for samples from Panj reach cutting the Shakhdara Dome, green dotted line: linear regression for samples north of the Shakhdara Dome (north) excluding TA090908A, $\mathrm{R}^{2}$ : correlation coefficient, mean incision: arithmetic mean of respective incision rates in mm/yr, m a.r.l.: meters above river level, SAD: Shakhdara-Alichur Dome, DFZ: Darvaz Fault Zone).

\subsection{Geomorphometric analyses}

The Panj has a non-equilibrated longitudinal river profile (Fig. 8). The fit of graded river profile segments (Fuchs et al., 2013b) suggests a composite river by detecting several local base levels in areas of low riverbed slope. The local base levels coincide with Panj reaches where it flows westward, parallel to the southern boundaries of the Shakhda and Yazgulom domes. Downstream of the local base levels, northward-deflected reaches of the Panj display prominent convex profiles and increased riverbed slopes.

The deviations of the Panj profile from a graded river are expressed by the Hack Index (Fig. 8). The Hack Index highlights an abrupt increase in riverbed steepness directly upstream of the Wakhan confluence and corresponding base level at the southern boundary of the Shakhdara Dome. The second zone of high Hack Index corresponds to a knickpoint downstream of the local base level at the southern boundary of the Yazgulom Dome. The Hack Index also indicates deviations from an equilibrated river downstream of the Vanj confluence. However, the transitional stage is difficult to evaluate because of uncertainties in the extracted river profile. Transitional stages of profile adjustment are further indicated by two zones of elevated Hack Index that coincide with convex profile zones, such as where the northward-deflected Panj cuts across the Shakhdara Dome.

\section{Discussion}

\subsection{Effects of temporal averaging}

The mean incision rates represent average conditions over the dated time interval. If the fluvial dynamic is disturbed by climatic, tectonic or hydrological forcing (e.g. 


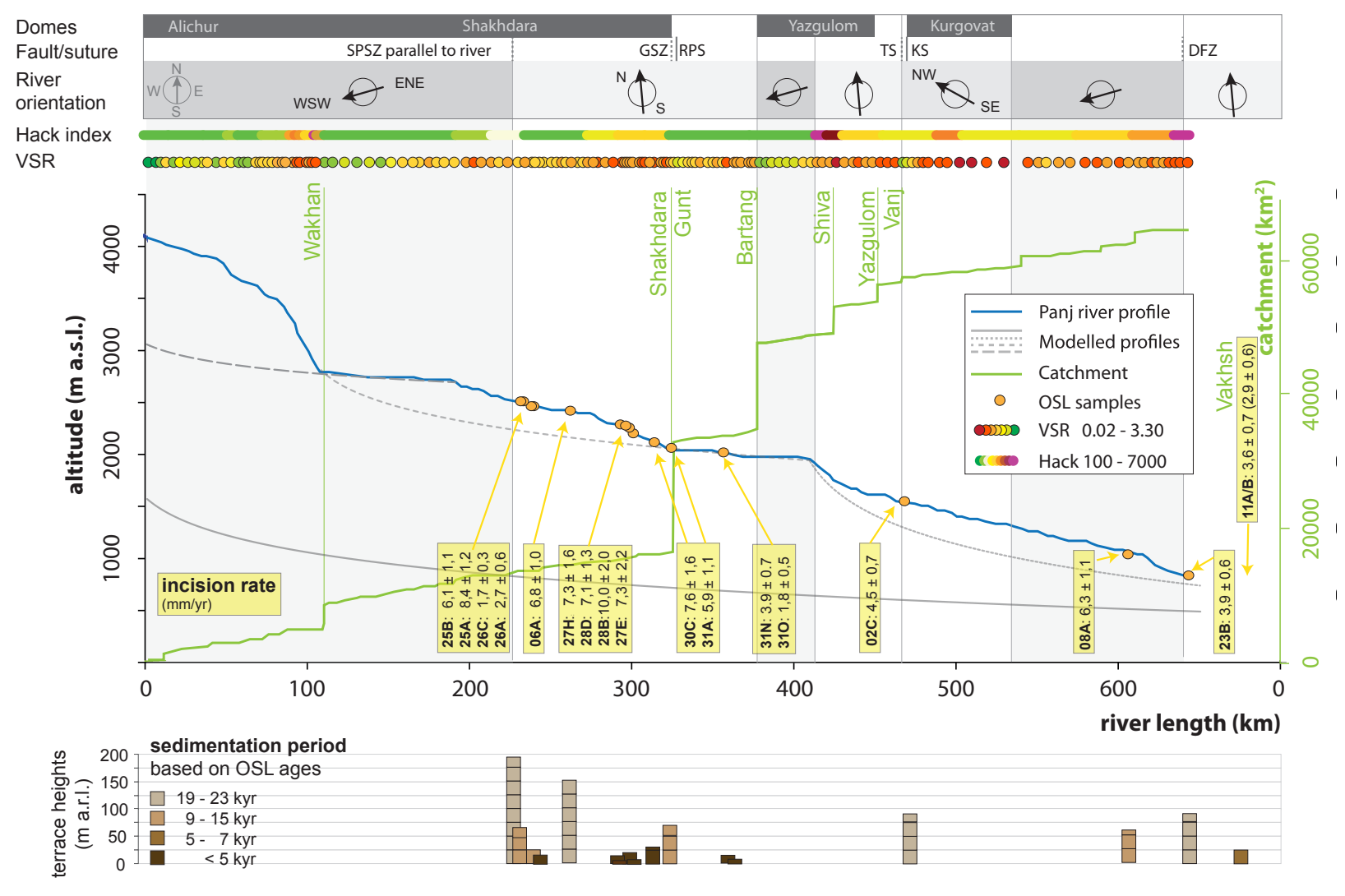

Figure 8: Longitudinal profile of the Panj. Summary of parameters for fluvial incision including OSL-based incision rates, modeled profiles of graded river segments and catchment area compared to river orientation and tectonic structures. Terrace heights and ages are given below the profile (kyr: thousand years, m a.s.l.: meters above sea level, $\mathrm{m}$ a.r.l.: meters above river level, VSR: valley shape ratio, SPSZ: Southern Pamir Shear Zone, GSZ: Gunt Shear Zone, RPS: Rushan-Psart Suture, TS: Tanymas Suture, KS: Kunlun Suture, DF: Darvaz Fault Zone). The longitudinal profile and VSR were modified after Fuchs et al. (2013b).

deglaciation, local uplift, river capture), fluvial response will depend on the magnitude frequency distribution of geomorphic events (Wolman and Miller, 1960). Incision rates from young terraces likely record the effects of highfrequency low-magnitude disturbances, while old terraces reveal conditions that likely average also over low-frequency high-magnitude disturbances.

We did not find increasing or decreasing incision rates over the last $\sim 26 \mathrm{kyr}$ although climatic conditions changed considerably since the last glaciation at the Pamir Plateau. Timescale independent incision is indicated by the correlation of heights and ages between terraces along the Shakhdara Dome and between terraces associated to westward river reaches. Determined rates also correspond to the long-term indication from the river profile and valley morphology. The consistency over timescales suggests no influence from the Sadler effect (Sadler, 1981). In other words, we use the hiatus in incision that is represented by local, brief sedimentation. This hiatus is of short duration compared to the averaged time interval of incision recorded in the studied terraces.

\subsection{Role of climate on terrace formation}

OSL ages of sampled terraces date the local deposition of fluvial sediments over the last $26 \mathrm{kyr}$ along the Panj at the western Pamir margin. The dated time range spans the period since the last glacial advance during early MIS 2 on the Pamir Plateau (Zech et al., 2005a; Abramowski et al., 2006; Röhringer et al., 2012). The oldest dated terraces of $(23 \pm 2.9) \mathrm{kyr}$ to $(19 \pm 2.9) \mathrm{kyr}$ coincide exposure ages of moraines from the last glacial advance (cf. Fig. 2). Panj terraces with ages of $(14.8 \pm 2.4) \mathrm{kyr}$ to $(9.1 \pm 1.6) \mathrm{kyr}$ may correspond to minor re-advances or recessional glacial stages during the transition of MIS 2 and MIS 1 (cf. Fig. 2) reported by Röhringer et al. (2012).

Apart from these two cycles of contemporaneous deposition of fluvial sediments in the Panj valley and glacial sediments on the plateau, there is no further evidence of glacial cycles driving terrace aggregation. We did not find older terraces along the Panj that would coincide with the pre-MIS 2 glaciations on the plateau (Zech et al., 2005a; Abramowski et al., 2006; Röhringer et al., 2012). The glacial advances during MIS 4 and earlier were more extensive and therefore probably had a greater impact on the river system. Fluvial sediments were either not deposited 
in the Panj valley before MIS 2 or else have been removed by erosion. Alternatively, the long-lasting melting inferred from the MIS 3 hummocky moraines (Zech et al., 2005b) may have smoothened the effects of discharge and sediment transport and hence on terrace aggradation corresponding to glacial cycles before $23 \mathrm{kyr}$. In addition, during MIS 2 and MIS 2/1 there is little distinction between the two older terrace generations due to overlapping age errors. There is no evidence to suggest that deposition of the youngest terraces of $<5 \mathrm{kyr}$ was coeval with a glacial event on the plateau. However, there is a lack of data on glacial advances since MIS 1 on the Pamir Plateau. The different timing of the Vakhsh terrace formation is attributed to the catchment north of the MPT, with no link to the glacial cycles on the Pamir Plateau.

Assuming climatic control on terrace formation would imply regionally consistent terraces ages and heights above the modern river. The older Panj terraces that are contemporaneous with glacial cycles are located close to confluences with tributaries draining the plateau or along reaches with a westward flow direction. In contrast, no terraces of comparable age to the glaciations (MIS 2 and MIS 2/1) were found in the widened valley at the confluence with Bartang River or at the junction with the Yazgulom River. The $<5$ kyr terraces show no links to the Plateau glaciations as they are not located close to a westward-draining tributary. Furthermore, the lack of paired terraces, terrace staircases or thick fluvial deposits is not consistent with prolonged, regionally consistent periods of sedimentation. The considerable variation in the height of terraces above the modern Panj cannot be explained by regional climatic forcing alone.

\subsection{Role of rock types, catchment geometry and tectonic structures}

The OSL-based terrace incision rates correlate with location along the Panj rather than timing of terrace formation (Fig. 7). Local rates agree to the pattern shown in the river profile, Hack Index and VSR (Fig. 8). Accordingly, incision rates derived from terraces within the lowermost $\sim 200 \mathrm{~m}$ of the valley are consistent with the long-term fluvial conditions recorded in stream gradient and valley morphology. Westward flowing reaches along southern dome boundaries show consistently low fluvial incision. Across the domes, incision shows high rates. The pattern fits with the idea of river capture across the Pamir domes that connect local base levels in westward reaches where the river corresponds to the predominant drainage orientation in Pamir.

A strong contrast in incision rates suggests a change in local conditions at the Shakhdara Dome, where the Panj turns to flow northwards (Fig. 8). Low incision rates of $1.4-3.3 \mathrm{~mm} / \mathrm{yr}$ (including the uncertainty range) relate to the river flowing parallel to the SPSZ along the southern rim of the Shakhdara Dome. This river reach is characterized by wide valleys and low riverbed slopes. The graded river profile indicates a local base level at
$2800 \mathrm{~m}$ a.s.l. (Fig. 8). All terraces along the reach crossing the Shakhdara Dome yield an average incision rate of $7.3 \mathrm{~mm} / \mathrm{yr}$ (Fig. 7) that is high compared to the Panj average $(5.6 \mathrm{~mm} / \mathrm{yr})$. The high rates are consistent between terraces with ages covering the last $\sim 25 \mathrm{kyr}$. The intense fluvial incision corresponds to elevated Hack Indices and steepened valleys (Fig. 8). The abrupt change of fluvial incision parallel to and across the Shakhdara Dome suggests structural control, while rock type or catchment show no major changes. The change in fluvial response supports an assumed northward river capture across the Shakhdara Dome. In addition, the convex shape in the river profile may serve as an indication of relative uplift along active or re-activated dome-bounding faults.

Low incision rates of $1.3-4.6 \mathrm{~mm} / \mathrm{yr}$ (including the uncertainty range) correspond to low Hack Indices north of the Shakhdara Dome. VSR reveal relatively steep valleys until the river deflects westward and the valley widens parallel to the Yazgulom Dome (Fig. 8). The Panj develops a concave profile that indicates a local base level at $\sim 2000 \mathrm{~m}$ a.s.l. along the southern rim of the Yazgulom Dome (Fig. 8). The discharge increase at the confluences with the Gunt and Shakhdara rivers has not led to the development of a knickpoint in the river profile nor did that with the Bartang River. An influence from changes in rock types is not evident in the river profile. No terraces were found close to the main knickpoint in the Panj profile that coincides with the northward deflection at the Yazgulom Dome. Here, maximum values in both Hack Index and VSR suggest very high fluvial incision. Fuchs et al. (2013b) suggested that river capture linked the downstream reaches across the Yazgulom Dome.

Terraces downstream of the Yazgulom Dome reveal incision rates between $3.3 \mathrm{~mm} / \mathrm{yr}$ and $5.2 \mathrm{~mm} / \mathrm{yr}$ (including the uncertainty range) for the last $\sim 26 \mathrm{kyr}$. These incision rates are similar to that determined for the Vakhsh terrace. The river profile indicates a transient stage and shows no major effects from different rock types or river catchment increases. High Hack Indices and low VSR suggest high river incision over the long-term. The slightly higher incision rate of $(6.3 \pm 1.1) \mathrm{mm} / \mathrm{yr}$ represents a terrace sampled upstream of the DFZ (Fig. 8), the fault zone that forms the western boundary of the Pamir.

\section{Conclusion}

OSL dating of 16 Panj terraces reveals temporal patterns in terrace sedimentation and spatial variations in incision rates along the northward-deflected Panj and its downstream reaches. Sedimentation along the Panj has been locally restricted and short-lived during the last $\sim 26$ kyr. The oldest terraces of $(23.0 \pm 2.9) \mathrm{kyr}$ to $(19.0 \pm 2.9) \mathrm{kyr}$ and those of $(14.8 \pm 2.4) \mathrm{kyr}$ to $(9.1 \pm 1.6) \mathrm{kyr}$ are located where west-flowing reaches of the Panj river system connect to the north-flowing trunk at the western Pamir margin. The timing of terrace formation coincides with glacial advance and possible re-advances on the Pamir Plateau 
during early MIS 2 and the transition of MIS 2 to MIS 1. Such a link with glacial cycles was not found for terraces at the confluences between the Panj and the Bartang and Yazgulom rivers and for the young terraces of $<5 \mathrm{kyr}$. However, the timing of glacial cycles on the plateau is not sufficient to explain the considerable differences in terrace heights above the modern Panj for terraces of similar age.

The local incision rates yield an average of $5.6 \mathrm{~mm} / \mathrm{yr}$ for the terraces along the Panj. Variations are consistent with spatial patterns in the river profile and valley morphology. Overall, the differences in incision rates do not correspond to changes in rock type or catchment increases. Instead, they appear to vary depending on the underlying structural unit of the Pamir through which the Panj cuts. Low incision rates of $1.4-3.3 \mathrm{~mm} / \mathrm{yr}$ and $1.3-$ $4.6 \mathrm{~mm} / \mathrm{yr}$ were derived for the west-flowing reaches of the Panj, parallel to the southern boundaries of the Shakhdara and Yazgulom domes. Here, Hack Index and VSR values suggest a graded river that is approaching its local base level. The northward-deflected reach of the Panj crossing the Shakhdara Dome is characterized by an average incision rate of $7.3 \mathrm{~mm} / \mathrm{yr}$. The high incision rates during the last $\sim 26 \mathrm{kyr}$ are consistent with high Hack Indices and low VSR. The contrast in fluvial incision parallel to and across the Pamir domes supports the interpretation of northward river captures. Especially the coincidence of convex zones in the Panj profile with the location of Pamir domes may be explained by relative uplift along dome-bounding faults. Downstream of the Yazgulom Dome, fluvial incision of 3.3 $5.2 \mathrm{~mm} / \mathrm{yr}$ reflects a transient river reach. Rates are similar to that from the Vakhsh River terrace north of the Pamir. A terrace upstream of the DFZ indicates an increased river incision of $(6.3 \pm 1.1) \mathrm{mm} / \mathrm{yr}$ at the western boundary of the Pamir.

\section{Acknowledgments}

We are indebted to our friend and colleague M. Krbetschek who left us abruptly in 2012. Matthias was, still is, the spirit of the OSL lab at TU Bergakademie Freiberg. We owe him the possibility for dating these very complex samples. We thank the DFG for funding our research associated with the TIPAGE project. We also thank the Academy of Science of Tajikistan for supporting our fieldwork in 2009. We used GMT (Wessel, P. and W. H. F. Smith, New, improved version of the Generic Mapping Tools released, EOS Trans. AGU, 79, 579, 1998), QGIS (http://qgis.org/) and the R environment (http://www.r-project.org/) for most of the topographic data processing and the resulting figures. Topographic and land cover data are based on ASTER GDEM and MODIS MCD12Q1 data products that were obtained through the online Data Pool at the NASA Land Processes Distributed Active Archive Center (LP DAAC), located at the U.S. Geological Survey (USGS) Earth Resources Observation and Science (EROS) Center, Sioux Falls, South Dakota (https://lpdaac.usgs.gov/data_access).

\section{References}

\section{References}

Abramowski, U., Bergau, A., Seebach, D., Zech, R., Glaser, B., Sosin, P., Kubik, P.W., Zech, W., 2006. Pleistocene glaciations of Central Asia: Results from ${ }^{10} \mathrm{Be}$ surface exposure ages of erratic boulders from the Pamir (Tajikistan), and the Alay-Turkestan range (Kyrgyzstan). Quaternary Science Reviews 25, 1080-1096.

Aitken, M.J., 1998. An introduction to optical dating. The dating of Quaternary sediments by the use of photon-stimulated luminescence, Oxford University Press.

Amidon, W.H., Hynek, S.A., 2010. Exhumational history of the north central Pamir. Tectonics 29, TC5017.

Arnold, L.J., Bailey, R.M., Tucker, G.E., 2007. Statistical treatment of fluvial dose distributions from southern Colorado arroyo deposits. Quaternary Geochronology 2, 162-167.

Arnold, L.J., Roberts, R.G., 2009. Stochastic modelling of multigrain equivalent dose $\left(\mathrm{D}_{e}\right)$ distributions: Implications for OSL dating of sediment mixtures. Quaternary Geochronology 4, 204230 .

Bailey, R.M., Arnold, L.J., 2006. Statistical modelling of single grain quartz $\mathrm{D}_{e}$ distributions and an assessment of procedures for estimating burial dose. Quaternary Science Reviews 25, 2475-2502.

Bershaw, J., Garzione, C.N., Schoenbohm, L., Gehrels, G., Tao, L., 2012. Cenozoic evolution of the Pamir plateau based on stratigraphy, zircon provenance, and stable isotopes of foreland basin sediments at Oytag (Wuyitake) in the Tarim Basin (west China). Journal of Asian Earth Sciences 44, 136-148.

Bridgland, D., Westaway, R., 2008. Climatically controlled river terrace staircases: A worldwide Quaternary phenomenon. Geomorphology 98, 285-315.

Brookfield, M.E., 2008. Evolution of the great river systems of southern Asia during the Cenozoic India-Asia collision: Rivers draining north from the Pamir syntaxis. Geomorphology 100, 296-311.

Brunel, M., Arnaud, N., Tapponnier, P., Pan, Y., Wang, Y., 1994. Kongur Shan normal fault: Type example of mountain building assisted by extension (Karakoram fault, eastern Pamir). Geology 22, 707-710.

Bull, B.W., 2007. Tectonic geomorphology of mountains - A new approach to paleoseismology. Blackwell Publishing, Oxford.

Burbank, D.W., Anderson, R.S., 2001. Tectonic geomorphology. Wiley-Blackwell.

Burbank, D.W., Leland, J., Fielding, E., Anderson, R., Brozovic, N., Reid, M.R., Duncan, C., 1996. Bedrock incision, rock uplift and threshold hillslopes in the northwestern Himalayas. Nature 379, 505-510.

Burtman, V.S., Molnar, P., 1993. Geological and physical evidence for deep subduction of continental crust beneath the Pamir. GSA Special Papers 281, 1-76.

Carcaillet, J., Mugnier, J.L., Koçi, R., Jouanne, F., 2009. Uplift and active tectonics of southern Albania inferred from incision of alluvial terraces. Quaternary Research 71, 465-476.

Cowgill, E., 2010. Cenozoic right-slip faulting along the eastern margin of the Pamir salient, northwestern China. Geological Society of America Bulletin 122, 145-161.

Cunningham, A.C., Wallinga, J., 2010. Selection of integration time intervals for quartz OSL decay curves. Quaternary Geochronology $5,657-666$.

Cunningham, A.C., Wallinga, J., Minderhoud, P.S.J., 2011. Expectations of scatter in equivalent-dose distributions when using multi-grain aliquots for OSL dating. Geochronometria 38, 424431 .

Demoulin, A., 1998. Testing the tectonic significance of some parameters of longitudinal river profiles: The case of the Ardenne (Belgium, NW Europe). Geomorphology 24, 189-208.

Demoulin, A., 2011. Basin and river profile morphometry: A new index with a high potential for relative dating of tectonic uplift. Geomorphology 126, 97-107.

Ducea, M.N., Lutkov, V., Minaev, V., Hacker, B.R., Ratschbacher, L., Luffi, P., Schwab, M., Gehrels, G.E., McWilliams, M., Ver- 
voort, J., Metcalf, J., 2003. Building the Pamirs: The view from the underside. Geological Society of America 31, 849-852.

Duller, G.A.T., 1994. Luminescence dating of poorly bleached sediments from Scotland. Quaternary Geochronology 13, 521-524.

Duller, G.A.T., 2007. Software ANALYST

Duller, G.A.T., 2008. Single-grain optical dating of Quaternary sediments: Why aliquot size matters in luminescence dating. Boreas $37,589-612$

Fan, G., Nil, J.F., Wallace, T.C., 1994. Active tectonics of the Pamir and Karakorum. Journal of Geophysical Research 99, 7131-7160.

Finnegan, N.J., Schumer, R., Finnegan, S., 2014. A signature of transience in bedrock river incision rates over timescales of $10^{4}$ $10^{7}$ years. Nature 505, 391-394.

Formento-Trigilio, M.L., Burbank, D.W., Nicol, A., Shulmeister, J., Rieser, U., 2002. River response to an active fold-and-thrust belt in a convergent margin setting, North Island, New Zealand. Geomorphology 49, 125-152.

Fuchs, M., Lang, A., 2001. OSL dating of coarse-grain fluvial quartz using single-aliquot protocols on sediments from NE-Peloponnese, Greece. Quaternary Science Reviews 20, 783-787.

Fuchs, M., Straub, J., Zoeller, L., 2005. Residual luminescence signals of recent river flood sediments: A comparison between quartz and feldspar of fine- and coarse-grain sediments. Ancient TL 23, $25-30$.

Fuchs, M.C., Böhlert, R., Krbetschek, M., Preusser, F., Egli, M., 2013a. Exploring the potential of luminescence methods for dating Alpine rock glaciers. Quaternary Geochronology 18, 17-33.

Fuchs, M.C., Gloaguen, R., Pohl, E., 2013b. Tectonic and climatic forcing on the Panj river system during the Quaternary. International Journal of Earth Sciences 102, 1985-2003.

Galbraith, R.F., Green, P.F., 1990. Estimating the component ages in a finite mixture. Nuclear Tracks and Radiation Measurements $17,197-206$.

Galbraith, R.F., Roberts, R.G., Laslett, G.M., Yoshida, H., Olley, J.M., 1999. Optical dating of single and multiple grains of quartz from Jinmium Rock Shelter, Northern Australia: Part I, Experimental design and statistical models. Archaeometry 41, 339-364.

Hack, J.T., 1957. Studies of longitudinal stream profiles in Virginia and Maryland. U.S. Geological Survey Professional Paper , 1-59.

Hack, J.T., 1973. Stream-profile analysis and stream-gradient index. Jour. Research US Geol. Survey 1, 421-429.

Hancock, G.S., Anderson, R.S., 2002. Numerical modeling of fluvial strath-terrace formation in response to oscillating climate. Geological Society of America Bulletin 114, 1131-1142.

Heer, A.J., Adamiec, G., Moska, P., 2012. How many grains are there on a single aliquot? Ancient TL 30, 9-16.

Hubbard, M.S., Grew, E.S., Hodges, K.V., Yates, M.G., Pertsev, N.N., 1999. Neogene cooling and exhumation of upperamphibolite-facies 'whiteschists' in the southwest Pamir Mountains, Tajikistan. Tectonophysics 305, 325-337.

Ischuk, A., Bendick, R., Rybin, A., Molnar, P., Khan, S.F., Kuzikov, S., Mohadjer, S., Saydullaev, U., Ilyasova, Z., Schelochkov, G., Zubovich, A.V., 2013. Kinematics of the Pamir and Hindu Kush regions from GPS geodesy. Journal of Geophysical Research: Solid Earth 118, 2408-2416.

Jeong, G.Y., Choi, J.H., 2012. Variations in quartz OSL components with lithology, weathering and transportation. Quaternary Geochronology 10, 320-326.

Koulakov, I., Sobolev, S.V., 2006. A tomographic image of Indian lithosphere break-off beneath the Pamir-Hindukush region. Geophysical Journal International 164, 425-440.

Krbetschek, M.R., Rieser, U., Zoeller, L., Heinicke, J., 1994. Radioactive disequilibria in palaeodosimetric dating of sediments. Radiation Measurements 23, 485-489.

Kreutzer, S., Schmidt, C., Fuchs, M.C., Dietze, M., Fischer, M., Fuchs, M., 2012. Introducing an R package for luminescence dating analysis. Ancient TL 30, 1-8.

Kulig, G., 2005. Erstellung einer Auswertesoftware zur Altersbestimmung mittels Lumineszenzverfahren unter spezieller Beruecksichtigung radioaktiver Ungleichgewichte in der 238-U-Zerfallsreihe. BSc thesis, Faculty of Mathematics and Network Computing, TU
Bergakademie Freiberg, unpublished.

Leland, J., Reid, M.R., Burbank, D.W., Finkel, R.C., Caffee, M.W., 1998. Incision and differential bedrock uplift along the Indus River near Nanga Parbat, Pakistan Himalaya, from ${ }^{10} \mathrm{Be}$ and ${ }^{26} \mathrm{Al}$ exposure age dating of bedrock straths. Earth and Planetary Science Letters 154, 93-107.

Li, B., Li, S.H., Wintle, A., 2008. Overcoming environmental dose rate changes in luminescence dating of waterlain deposits. Geochronometria 30, 33-40.

Lukens, C.E., Carrapa, B., Singer, B.S., 2012. Miocene exhumation of the Pamir revealed by detrital geothermochronology of Tajik rivers. Tectonics 31

Mohadjer, S., Bendick, R., Ischuk, A., Kuzikov, S., Kostuk, A., Saydullaev, U., Lodi, S., Kakar, D.M., Wasy, A., Khan, M.A., Molnar, P., Bilham, R., Zubovich, A.V., 2010. Partitioning of India-Eurasia convergence in the Pamir-Hindu Kush from GPS measurements. Geophysical Research Letters 37, n/a-n/a.

Murray, A.S., Olley, J.M., 2002. Precision and accuracy in the optically stimulated luminescence dating of sedimentary quartz: A status review. Geochronometria 21, 1-16.

Murray, A.S., Wintle, A.G., 2000. Luminescence dating of quartz using an improved single- aliquot regenerative-dose protocol. Radiation Measurements 32, 57-73.

Murray, A.S., Wintle, A.G., 2003. The single aliquot regenerative dose protocol: Potential for improvements in reliability. Radiation Measurements 37, 377-381.

Olley, J., Caitcheon, G., Murray, A., 1998. The distribution of apparent dose as determined by optical stimulated luminescence in small aliquots of fluvial quartz: Implications for dating young sediments. Quaternary Geochronology 17, 1033-1040.

Owen, L.A., Caffee, M.W., Finkel, R.C., Seong, Y.B., 2008. Quaternary glaciation of the Himalayan-Tibetan orogen. Journal of Quaternary Science 23, 513-531.

Owen, L.A., Chen, J., Hedrick, K.A., Caffee, M.W., Robinson, A.C., Schoenbohm, L.M., Yuan, Z., Li, W., Imrecke, D.B., Liu, J., 2012. Quaternary glaciation of the Tashkurgan Valley, Southeast Pamir. Quaternary Science Reviews 47, 56-72.

Owen, L.A., Finkel, R.C., Caffee, M.W., Gualtieri, L., 2002a. Timing of multiple late Quaternary glaciations in the Hunza Valley, Karakoram Mountains, northern Pakistan: Defined by cosmogenic radionuclide dating of moraines. Geological Society of America Bulletin 114, 593-604.

Owen, L.A., Kamp, U., Spencer, J.Q., Haserodt, K., 2002b. Timing and style of Late Quaternary glaciation in the eastern Hindu Kush, Chitral, northern Pakistan: A review and revision of the glacial chronology based on new optically stimulated luminescence dating. Quaternary International 97-98, 41-55.

Pan, B., Su, H., Hu, Z., Hu, X., Gao, H., Li, J., Kirby, E., 2009. Evaluating the role of climate and tectonics during non-steady incision of the Yellow River: Evidence from a 1.24 Ma terrace record near Lanzhou, China. Quaternary Science Reviews 28, 3281-3290

Pazzaglia, F.J., Gardner, T.W., Merritts, D.J., 1998. Bedrock fluvial incision and longitudinal profile development over geologic time scales determined by fluvial terraces. Geophysical Monograph Series, American Geophysical Union, Washington.

Pegler, G., Das, S., 1998. An enhanced image of the Pamir-Hindu Kush seismic zone from relocated earthquake hypocentres. Geophysical Journal International 134, 573-595.

Pietsch, T.J., Olley, J.M., Nanson, G.C., 2008. Fluvial transport as a natural luminescence sensitiser of quartz. Quaternary Geochronology $3,365-376$.

Preusser, F., Ramseyer, K., Schlüchter, C., 2006. Characterisation of low OSL intensity quartz from the New Zealand Alps. Radiation Measurements 41, 871-877.

Reigber, C., Michel, G.W., Galas, R., Angermann, D., Klotz, J., Chen, J.Y., Papschev, A., Arslanov, R., Tzurkov, V.E., Ishanov, M.C., 2001. New space geodetic constraints on the distribution of deformation in Central Asia. Earth and Planetary Science Letters 191, 157-165.

Robinson, A.C., 2009. Geologic offsets across the northern Karako- 
rum fault: Implications for its role and terrane correlations in the western Himalayan-Tibetan orogen. Earth and Planetary Science Letters 279, 123-130.

Robinson, A.C., Yin, A., Lovera, O.M., 2010. The role of footwall deformation and denudation in controlling cooling age patterns of detachment systems: An application to the Kongur Shan extensional system in the Eastern Pamir, China. Tectonophysics 496, 28-43.

Robinson, A.C., Yin, A., Manning, C.E., Harrison, T.M., Zhang, S.H., Wang, X.F., 2007. Cenozoic evolution of the eastern Pamir: Implications for strain-accommodation mechanisms at the western end of the Himalayan-Tibetan orogen. Geological Society of America Bulletin 119, 882-896.

Rodnight, H., Duller, G.A.T., Wintle, A.G., Tooth, S., 2006. Assessing the reproducibility and accuracy of optical dating of fluvial deposits. Quaternary Geochronology 1, 109-120.

Röhringer, I., Zech, R., Abramowski, U., Sosin, P., Aldahan, A., Kubik, P.W., Zöller, L., Zech, W., 2012. The late Pleistocene glaciation in the Bogchigir Valleys (Pamir, Tajikistan) based on ${ }^{10}$ Be surface exposure dating. Quaternary Research 78, 590-597.

Sadler, P.M., 1981. Sediment accumulation rates and the completeness of stratigraphic sections. The Journal of Geology 89, 569-584.

Schmidt, J., Hacker, B.R., Ratschbacher, L., Konstanze, S.b., Stearns, M., Kylander-Clark, A., Cottle, J.M., Alexander, A., Webb, G., Gehrels, G., Minaev, V., 2011. Cenozoic deep crust in the Pamir. Earth and Planetary Science Letters 312, 411-421.

Schneider, F.M., Yuan, X., Schurr, B., Mechie, J., Sippl, C., Haberland, C., Minaev, V., Oimahmadov, I., Gadoev, M., Radjabov, N., Abdybachaev, U., Orunbaev, S., Negmatullaev, S., 2013. Seismic imaging of subducting continental lower crust beneath the Pamir. Earth and Planetary Science Letters , 1-11.

Schwab, M., Ratschbacher, L., Siebel, W., McWilliams, M., Minaev, V., Lutkov, V., Chen, F., Stanek, K., Nelson, B., Frisch, W. Wooden, J.L., 2004. Assembly of the Pamirs: Age and origin of magmatic belts from the southern Tien Shan to the southern Pamirs and their relation to Tibet. Tectonics 23, TC4002.

Shahzad, F., Gloaguen, R., 2011a. TecDEM A MATLAB based toolbox for tectonic geomorphology, Part 1 Drainage network preprocessing and stream profile analysis. Computers and Geosciences $37,250-260$.

Shahzad, F., Gloaguen, R., 2011b. TecDEM A MATLAB based toolbox for tectonic geomorphology, Part 2 Surface dynamics and basin analysis. Computers and Geosciences 37, 261-271.

Singh, T., Awasthi, A.K., 2010. Stream profiles as indicator of active tectonic deformation along the Intra-Foreland Thrust, Nahan Salient, NW India. Current Science 98, 95-97.

Sippl, C., Schurr, B., Yuan, X., Mechie, J., Schneider, F.M., Gadoev M., Orunbaev, S., Oimahmadov, I., Haberland, C., Abdybachaev, U., Minaev, V., Negmatullaev, S., Radjabov, N., 2013. Geometry of the Pamir-Hindu Kush intermediate-depth earthquake zone from local seismic data. Journal of Geophysical Research: Solid Earth 118, 1438-1457.

Snyder, N.P., Whipple, K.X., Tucker, G.E., Merritts, D.J., 2000 Landscape response to tectonic forcing: Digital elevation model analysis of stream profiles in the Mendocino triple junction region, northern California. Geological Society of America Bulletin 112 1250-1263.

Stokes, M., Cunha, P.P., Martins, A.A., 2012. Techniques for analysing Late Cenozoic river terrace sequences. Geomorphology 165-166, 1-6.

Strahler, A., Muchoney, D., Borak, J., Friedl, M., Gopal, S., Lambin, E., Moody, A., 1999. MODIS Land Cover Product Algorithm Theoretical Basis Document (ATBD) Version 5.0 , 1-59.

Strecker, M.R., Frisch, W., Hamburger, M.W., Ratschbacher, L., Semiletkin, S., Zamoruyev, A., Sturchio, N., 1995. Quaternary deformation in the Eastern Pamirs, Tadzhikistan and Kyrgyzstan. Tectonics 14, 1061-1079.

Stübner, K., Ratschbacher, L., Weise, C., Chow, J., Hofmann, J., Khan, J., Rutte, D., Sperner, B., Pfänder, J.A., Hacker, B.R., Dunkl, I., Tichomirowa, M., Stearns, M.A., Bahram, I., Gadoev, M., Gloaguen, R., Jonckheere, R., Kanaev, E., Minaev,
V., Oimahmadoc, I., Rajabov, N., Stanek, K.P., 2013. The giant Shakhdara migmatitic gneiss dome, Pamir, India-Asia collision zone, II: Timing of dome formation. Tectonics, $n / a-n / a$.

Trifonov, V.G., 1978. Late Quaternary tectonic movements of western and central Asia. Geological Society of America Bulletin 89, 1059 .

Vandenberghe, J., Wang, X., Lu, H., 2011. Differential impact of small-scaled tectonic movements on fluvial morphology and sedimentology (the Huang Shui catchment, NE Tibet Plateau). Geomorphology 134, 171-185.

Vlasov, N.G., Dyakov, Y.A., Cherev, E.S., 1991. Geological map of the Tajik SSR and adjacent territories.

Wallinga, J., 2002. Optically stimulated luminescence dating of fluvial deposits: A review . Boreas 31, 303-322.

Wang, A., Smith, J.A., Wang, G., Zhang, K., Xiang, S., Liu, D., 2009. Late Quaternary river terrace sequences in the eastern Kunlun Range, northern Tibet: A combined record of climatic change and surface uplift. Journal of Asian Earth Sciences 34, 532-543.

Westaway, R., Bridgland, D.R., Sinha, R., Demir, T., 2009. Fluvial sequences as evidence for landscape and climatic evolution in the Late Cenozoic: A synthesis of data from IGCP 518. Global and Planetary Change 68, 237-253.

Wheeler, R., Bufe, C.G., Johnson, M.L., Dart, R.L., 2005. Seismotectonic Map of Afghanistan, with Annotated Bibliography.

Wintle, A.G., 1973. Anomalous fading of thermo-luminescence in mineral samples . Nature 245, 143-144.

Wolman, J.G., Miller, J.P., 1960. Magnitude and frequency of forces in geomorphic processes. Journal of Geology 68, 54-74.

Zech, R., Abramowski, U., Glaser, B., Sosin, P., Kubik, P.W., Zech, W., 2005a. Late Quaternary glacial and climate history of the Pamir Mountains derived from cosmogenic ${ }^{10}$ Be exposure ages. Quaternary Research 64, 212-220.

Zech, R., Glaser, B., Sosin, P., Kubik, P.W., Zech, W., 2005b. Evidence for long-lasting landform surface instability on hummocky moraines in the Pamir Mountains (Tajikistan) from ${ }^{10} \mathrm{Be}$ surface exposure dating. Earth and Planetary Science Letters 237, 453461 . 